\title{
2-2014
}

\section{Complexity, Efficiency, and Fairness of Multi-Product Monopoly Pricing}

Eugenio J. Miravete

Katja Seim

University of Pennsylvania

Jeff Thurk

Follow this and additional works at: https://repository.upenn.edu/marketing_papers

Part of the Business Administration, Management, and Operations Commons, Business Analytics Commons, Management Sciences and Quantitative Methods Commons, Marketing Commons, Other Public Affairs, Public Policy and Public Administration Commons, Policy Design, Analysis, and Evaluation Commons, Sales and Merchandising Commons, and the Taxation Commons

\section{Recommended Citation}

Miravete, E. J., Seim, K., \& Thurk, J. (2014). Complexity, Efficiency, and Fairness of Multi-Product Monopoly Pricing. Retrieved from https://repository.upenn.edu/marketing_papers/354

This is an unpublished manuscript.

This paper is posted at ScholarlyCommons. https://repository.upenn.edu/marketing_papers/354

For more information, please contact repository@pobox.upenn.edu. 


\title{
Complexity, Efficiency, and Fairness of Multi-Product Monopoly Pricing
}

\begin{abstract}
The Pennsylvania Liquor Control Board administers the purchase and sale of wine and spirits and is mandated to charge a uniform $30 \%$ markup on all products. We use an estimated discrete choice model of demand for spirits, together with information on wholesale prices, to assess the implications of this policy. We find that failure to account for the correlation between demographics and consumption patterns leads to lower prices than those charged by a profit-maximizing, multi-product monopolist. Using product-specific markups leads to higher prices on average, less quantity consumed, an $11 \%$ increase in total profits, and greater welfare. The current one-size-fits-all pricing rule ignores variations in demand elasticities resulting in the implicit taxation of high-income and educated households by raising the prices of spirits they prefer (vodka and whiskey) while lowering the price of products favored by low-income and minority households (gin and rum).
\end{abstract}

\section{Keywords}

multi-product price discrimination, complex pricing, taxation by regulation

\section{Disciplines}

Business | Business Administration, Management, and Operations | Business Analytics | Management Sciences and Quantitative Methods | Marketing | Other Public Affairs, Public Policy and Public Administration | Policy Design, Analysis, and Evaluation | Sales and Merchandising I Taxation

\section{Comments}

This is an unpublished manuscript. 


\title{
Complexity, Efficiency, and Fairness of Multi-Product Monopoly Pricing*
}

\author{
Eugenio J. Miravete ${ }^{\dagger} \quad$ Katja Seim ${ }^{\ddagger} \quad$ Jeff Thurk $^{\S}$
}

February 14, 2014

\begin{abstract}
The Pennsylvania Liquor Control Board administers the purchase and sale of wine and spirits and is mandated to charge a uniform $30 \%$ markup on all products. We use an estimated discrete choice model of demand for spirits, together with information on wholesale prices, to assess the implications of this policy. We find that failure to account for the correlation between demographics and consumption patterns leads to lower prices than those charged by a profit-maximizing, multi-product monopolist. Using product-specific markups leads to higher prices on average, less quantity consumed, an $11 \%$ increase in total profits, and greater welfare. The current one-size-fits-all pricing rule ignores variations in demand elasticities resulting in the implicit taxation of high-income and educated households by raising the prices of spirits they prefer (vodka and whiskey) while lowering the price of products favored by low-income and minority households (gin and rum).
\end{abstract}

Keywords: Multi-Product Price Discrimination, Complex Pricing, Taxation by Regulation.

JEL Codes: L12, L21, L32

* We thank Thomas Krantz at the Pennsylvania Liquor Control Board and Mike Ehtesham at the National Alcohol Beverage Control State Association, Inc., for helping us to get access to the data. We are also grateful for comments and suggestions received at several seminar and conference presentations, and in particular to Jeff Campbell and Joel Waldfogel. We are solely responsible for any remaining errors.

${ }^{\dagger}$ The University of Texas at Austin, Department of Economics, 2225 Speedway Stop 3100, Austin, Texas 78712-0301; Centre for Competition Policy/UEA; and CEPR, London, UK. Phone: 512-232-1718. Fax: 512-471-3510. E-mail: miravete@eco.utexas.edu; http://www.eugeniomiravete.com

${ }^{\ddagger}$ Wharton School, University of Pennsylvania, Philadelphia, PA 19104-6372. E-mail: kseim@wharton.upenn.edu; https://bepp.wharton.upenn.edu/profile/712/

$\S$ University of Notre Dame, Department of Economics, Notre Dame, IN 46556. E-mail: jthurk@nd.edu; http://www.nd.edu/ jthurk/ 


\section{Introduction}

Business intelligence in the form of use and analysis of transaction data is an increasingly important tool in firms' inventory, marketing, and pricing decisions. Over a decade ago, Wal-Mart incorporated predictions from the National Weather Service to overstock its centers along the expected path of a hurricane with not only flashlights and batteries, but also Pop-Tarts, as the analysis of sales data revealed that shoppers purchase ready-to-eat food in anticipation of power outages. Internet retailers such as Amazon.com are able to use customer purchase and location information to employ pricing schemes with near-individualized discounts and bundle offers. ${ }^{1}$ Outside the retail context, a plethora of airline tariffs screens consumers by preference for direct flights and time or day of departure, and even by price sensitivity as revealed by the day-of-week of the purchase (Puller and Taylor, 2012).

The availability of a wealth of transaction data allows firms in principle to implement the complex fully nonlinear tariffs with volume and/or bundling discounts commonly considered by economic theorists. ${ }^{2}$ And yet, in many industries, firms rarely use such complicated pricing strategies. For instance, consumer packaged goods, such as ice-cream and soda, come in many equally-priced varieties, as do titles at movie theaters (Orbach and Einav, 2007), despite apparent differences in attributes and quality. Depending on the setting, such flat-rate pricing can entail significant efficiency losses as exemplified by retail electricity markets with highly volatile demand (Borenstein and Holland, 2005).

The goal of this paper is to measure the magnitude of foregone rents and the distributional consequences of such simple pricing strategies. We study the spirit market in Pennsylvania where, as the consequence of a legal mandate, the state-run retail monopolist is the largest purchaser of alcohol in the United States and charges the same $30 \%$ percent markup on every item sold in every store, irrespective of local or product demand differences. Based on an estimated demand system for spirits, we assess the welfare and profit implications of this uniform markup policy. We compare it to other, more flexible, profit-maximizing pricing alternatives, not only to bound profit losses from uniform pricing, but also to evaluate the efficiency implications of and apparent motives behind the regulation. We do so in part

${ }^{1}$ See "A different game" and "Data, data everywhere" both at The Economist, February 25, 2010, and Mikians, Gyarmati, Erramilli and Laoutaris (2012).

${ }^{2}$ Recent examples in the theory literature include, e.g., Armstrong (1999) and Rochet and Choné (1998) for monopolies and Armstrong and Vickers (2001) and Rochet and Stole (2002) in competitive environments. Wilson (1993) surveys this rich literature. 
by addressing the implicit income redistribution induced by the one-size-fits-all pricing rule when customers, as we demonstrate, are heterogeneous in their product preferences.

Our analysis proceeds as follows. First, we estimate a standard multi-product discrete choice model of demand for spirits. We then use the estimated demand system to evaluate the profitability and welfare of alternative pricing policies. This requires estimates of the firm's marginal costs. Frequently, these can be recovered from markup estimates implied by the pricing first-order conditions for maximization of the firm's profit or an alternative social welfare objective (see, e.g., Berry, Levinsohn and Pakes, 1995). We instead rely on wholesale price information obtained directly from the agency. Thereby, we avoid having to specify the agency's objective function, which might - in addition to profitability - reflect distributional value judgments or attempts to control the important safety and health-related externalities associated with excessive alcohol consumption. Our estimates allow us to evaluate how far its stated or implicit goals are from those of a multi-product profit maximizing monopolist, as we can compare the current profits with the ones that would have been obtained under profit maximization.

We deliver several results. First, we show that the current pricing behavior of the Pennsylvania Liquor Control Board $(P L C B)$ is indistinguishable from that of a multiproduct, profit-maximizing monopolist constrained to use a uniform percent markup across its product line: The PLCB's mandated uniform 30\% markup is only slightly below the profit-maximizing $32 \%$ markup and the difference in total profits is negligible. Within the legal pricing constraint, this result suggests an objective function for the $P L C B$ that places weight primarily on producer rather than consumer surplus.

Given the negative externalities associated with excessive alcohol consumption, including traffic accidents, domestic violence, and health effects, it is not surprising that the $P L C B$ 's pricing behavior is inconsistent with an objective of total private welfare maximization, or equal weights for consumer and producer surplus, as the associated lower prices would promote consumption. At the same time, with sizable social costs, one might have expected a pattern to prices consistent with the $P L C B$ placing negative weight on (private) consumer surplus. We show that were the agency to ignore the correlations between consumer demographics and alcohol consumption patterns observed in the data, the profit-maximizing uniform markup is only $21.5 \%$. Thus, if the $P L C B$ had a belief of largely homogenous consumer preferences, it could have mistakenly concluded that a $30 \%$ markup was sufficiently high to reduce alcohol consumption while simultaneously generating revenue for the state. 
Next, we consider how much profit the $P L C B$ foregoes by using a uniform markup. A natural benchmark strategy, commonly employed by nationwide retailers, consists of setting markups at the product level, but charging the same price for a given product across the entire state. The freely chosen markups across products would then allow the $P L C B$ to benefit from statewide preference heterogeneity across spirits. We find that the average markup increases to $42.7 \%$ although this single number hides important differences across products: the average markup for expensive spirits decreases to $26.3 \%$, while for cheap spirits it increases to $67.4 \%$. Relative to a uniform markup rate, predicted profits increase substantially by $11.3 \%$, both due to higher average prices of chosen products and to the wider variation in markups. Total private welfare remains essentially unchanged as profit gains come at the expense of consumers whose surplus and consumption are $13 \%$ and $9 \%$ higher, respectively, under the current uniform markup. This also suggests that if the externalities of alcohol consumption were increasing in quantity sold and thus decreasing in price, the easy-to-implement product-level pricing strategy we consider would not only increase total profit, but may also improve total social welfare.

Moving beyond the aggregate implications for profit and consumer welfare, we then turn to a nuanced view of the winners and losers of the current simple pricing rule. We show that the $P L C B$ 's use of a uniform markup in the presence of heterogeneous consumer preferences has significant distributional consequences for different demographic groups. Making use of the rich variation of demographics across local markets, we tie the effects of alternative pricing strategies to consumer attributes by correlating predicted changes in units sold and consumer surplus from relaxing the uniform markup rate with observable demographics. By doing so, we investigate the political economy of regulated alcohol distribution from a frequently neglected perspective: the current uniform percent markup policy introduces important price distortions that redistribute rents from the firm to customers, but also between different customer groups, turning the $P L C B$ 's pricing into a taxation mechanism. Such redistribution via taxation is not exclusive to alcohol distribution, but common to many regulated industries. In the words of Posner (1971):

"... one the functions of regulation is to perform distributive and allocative chores usually associated with the taxing or financial branch of government. (...) Uniform rates, based on averaging together the costs of services whose cost characteristics are in fact very different, are conspicuous features of regulated rate structures." 
In our case, the patterns of predicted price changes from relaxing the uniform pricing rule suggest that the uniform markup policy results, on average, in the underpricing of gin and rum relative to whiskey and vodka products. Since we find that low-income and minority households favor gins and rums, while demand for vodka is driven primarily by high-income, educated households, the current policy results in an implicit taxation of the latter households' alcohol consumption. This is an important result mostly neglected in public policy debates. We believe that our analysis is the first quantification of the incidence of taxation induced by a regulatory rule. ${ }^{3}$ Further, numerous studies have established a relationship between crime and alcohol prices and access. Thus, a likely unintended consequence of the current uniform $30 \%$ markup policy across all spirits, is the possibility of exacerbating these negative effects in areas with high crime rates. ${ }^{4}$

Finally, as a by-product of our analyses, we provide an upper bound estimate of the foregone rents of simple pricing by investigating a third-degree price discrimination (3DPD) strategy with prices varying across products and across local markets, here store areas. Despite the literature's deep-rooted interest, there are neither general results nor empirical evidence from a setting with a similar number of markets or products to ours that speak to the magnitudes of profit and welfare of $3 D P D$ relative to uniform pricing. From Robinson 1933, §15.5) to Aguirre, Cowan and Vickers (2010), economists have instead identified conditions for ranking profits and/or welfare in the two settings based on the curvatures of demand in the different markets served. ${ }^{5}$ In the absence of reasonable arguments for

${ }^{3}$ To the best of our knowledge, the redistribution effects of price discrimination have only been addressed in the $2 D P D$ case. Feldstein (1971) evaluates the equity and efficiency of a public monopolist's use of the optimal two-part tariff to market a service to a pool of consumers with different service valuations. Borenstein (2012) finds limited redistribution effects of increasing-block pricing in the regulated electricity market, while Borenstein and Davis (2012) show that cost-based pricing for natural gas entails substantial welfare losses.

4 Carpenter and Dobkin (2010) indicate that most studies find evidence that higher alcohol taxes prices deter at least some crimes (see, e.g., Markowitz, 2005). Similarly, availability of alcohol due to extended opening hours and proximity to retail outlets is linked to minor, property and violent crimes (Gyimah-Brempong, 2001; Heaton, 2012), with evidence of significantly more pronounced effects in low socioeconomic status neighborhoods (Teh 2008).

${ }^{5}$ A number of additional results exist on the sign, but not the magnitude, of the overall welfare effect. Schmalensee (1981) proves that if a monopolist faces constant marginal costs and independent demands in separate markets, welfare increases with $3 D P D$ provided overall output increases relative to uniform pricing, a result Katz (1983) later also established for 2DPD. Varian (1985) and Schwartz (1990) broaden Schmalensee's result to the cases of interdependent demands with non-decreasing marginal costs and of a general cost function that depends only on total output, respectively. Mauleg (1983) and Mauleg and Snyder (2006) explore related demand shape restrictions to derive bounds for the changes in welfare and profit, respectively, from moving to $3 D P D$. 
restricting the shape of demands, however, only a case-specific evaluation appears suitable. Our results show small, $4.2 \%$ incremental profit gains of $3 D P D$ relative to product-specific pricing. Accounting for the possibility of arbitrage across stores and for the managerial costs of implementing such a complex strategy given the sheer number of products and markets would likely erode much of these gains. Thus, our results support the profitable use of simple pricing strategies in an environment that is on its face conducive to segmentation. ${ }^{6}$

The paper is organized as follows. Section 2 reviews the current regulation of the distribution of alcoholic beverages in Pennsylvania and reports descriptive evidence supporting the existence of heterogeneous preferences for liquor consumption along demographic dimensions such as race, education, and income. Section 3 introduces the $P L C B$ store level sales data, presents a standard model of discrete choice demand, and discusses estimation details including parameter identification and our choice of instruments to address the possibility of spirit price endogeneity. Section 4 reports the estimates for our primary and alternative demand model specifications that together investigate the robustness of our results. We use the estimates in section 5 to compute optimal prices under alternative institutional pricing rules and to relate welfare changes from moving to such prices to observable local socioeconomic information. Evaluating these counterfactuals allows us to conclude that within the constraints of its regulation, the $P L C B$ behaves similarly to a profit maximizing, multi-product monopolist; that increased profitability from complex price discrimination schemes is limited; and that - abstracting from safety, health, or any other externalities induced by alcohol consumption - the current system acts as a taxing scheme on high-income households by lowering prices on their favored spirits only marginally compared to the average product. Section 6 concludes.

\section{The Pennsylvania Liquor Market}

Following Prohibition, Pennsylvania adopted one of the tightest regulations for the distribution and sale of alcoholic beverages of the 18 so-called control states that hold state

${ }^{6}$ In environments with asymmetric information, when second-degree price discrimination $(2 D P D)$ is used, Wilson (1993, §8.3) shows that a small number of tariff options can capture most of the surplus and Rogerson (2003) establishes that a single two-part tariff captures over $75 \%$ of total surplus. In the context of multi-product settings, Armstrong (1999) proves that a cost-based two-part tariff is asymptotically efficient and extracts almost the full surplus when a monopolist sells a sufficiently large number of products. On the empirical front, $\mathrm{Chu}$, Leslie and Sorensen (2011) conclude that simple tariffs based on bundle sizes closely approximate the profits from mixed bundling. 
monopolies over the distribution and/or retail of liquor. The $P L C B$ acts as a monopolist in the wholesale and retail distribution of wine and spirits, ${ }^{7}$ directly operating a system of 624 state-run stores (as of January 2005) spread across the state. ${ }^{8}$ More interestingly for the purpose of the present paper, the $P L C B$ enforces a centralized pricing system where all wines and spirits are subject to a uniform percent markup. ${ }^{9}$

This section describes the main features of the $P L C B$ 's pricing and presents descriptive evidence supporting the existence of heterogeneous preferences for liquor by different demographic groups. This serves as the point of departure of our research: if consumers are indeed heterogeneous, a uniform pricing rule across products regardless of their demand elasticities might overprice some spirits, relative to a more flexible pricing rule, and underprice others, thus leading to an implicit redistribution of income across households.

\subsection{Current Pricing}

The Pennsylvania State Legislature exerts regulatory control over several aspects of the daily operations of the stores. Most notably, as per the Pennsylvania Liquor Code (47 P.S. §1-101 et seq.) and the Pennsylvania Code Title 40, the legislature imposes a uniform markup rule upon the prices that the $P L C B$ charges both across products and across stores. Prices of wine and spirits are thus identical across the state. The legislature prescribes applying a $30 \%$ markup and an $18 \%$ liquor tax to the wholesale price, $c^{w}$. Accordingly, the retail price $p$ of a given product is calculated as $p=\left(c^{w} \times 1.3+\right.$ bottle fee $) \times 1.18$, where the bottle fee is a handling charge that amounts to $\$ 1.20$ for the products we consider. ${ }^{10}$ An additional $6 \%$ Pennsylvania sales tax is then applied to the posted price to generate the final price paid by the consumer. Table 1 reports the average 2005 prices of the spirit varieties that we study in this paper by spirit type.

7 The $P L C B$ also operates a privatized system for the sale of beer, allowing the controlled entry of private retailers.

${ }^{8}$ See Seim and Waldfogel $(2013, \S 2)$ for a detailed account of the welfare loses induced by the very limited entry allowed in the wine and spirit segment of the Pennsylvania market.

${ }^{9}$ This is but one type of price regulation. Corts (1995), for example, focuses on the price distortions induced by policies that impose a cap on a subset of a regulated monopolist's products classified as basic or essential to consumers.

10 The only exception to the prescribed $30 \%$ markup are price reductions authorized for products typically wines - that the $P L C B$ is in the process of removing from its product catalog once inventory has fallen to sufficiently low levels. 
Table 1: Prices by Spirit Type

\begin{tabular}{lrrrrr}
\hline \hline Spirit Type & Avg & Median & SD & Min & Max \\
\hline GIN & 14.32 & 10.99 & 6.36 & 5.99 & 28.99 \\
RUM & 12.35 & 12.49 & 2.74 & 5.49 & 21.99 \\
TEQUILA & 20.77 & 18.99 & 7.71 & 11.99 & 52.99 \\
VODKA & 15.71 & 13.99 & 5.54 & 5.69 & 30.99 \\
WHISKEY & 15.72 & 13.99 & 6.88 & 4.99 & 42.99 \\
\hline ALL PRODUCTS & 15.16 & 13.49 & 6.07 & 4.99 & 52.99 \\
\hline
\end{tabular}

Source: $P L C B$. Sales-weighted dollar averages of Pennsylvania liquor prices in 2005.

The $P L C B$ has limited ability to depart from this uniform percent markup rule. It operates seven outlet stores close to the state's borders, in an effort to address the border bleed of consumers who illegally import lower-priced products into Pennsylvania from neighboring states. While these stores offer wines and spirits at discounted prices, the PLCB remains within the uniform markup policy by selling products in the outlet stores not found in regular stores, for example multi-packs or unusual bottle sizes for a particular product. Controlling for these stores has little qualitative or quantitative effects on our results (related robustness checks are reported in Appendix B].

Due to the legislated pricing formula, any retail price changes originate in wholesale pricing decisions of the PLCB's suppliers - the distillers. The PLCB purchases spirits directly from manufacturers. A new product's wholesale price remains fixed for one year after introduction. For established products, the $P L C B$ adjust prices to accommodate cost increases on a quarterly basis, rotating through product categories according to preset schedules every reporting period, which are four-week long accounting periods typically beginning on a Thursday in the middle of the month. Requests for cost increases must be submitted three months ahead of the proposed date on which the cost increase becomes effective, while the less common cost decreases may be submitted at any time and are effective when approved by the $P L C B$. Thus each reporting period, the wholesale price of a subset of products is adjusted, translating into changes in the retail price.

Distillers also have the authority to temporarily change their wholesale price via a vendor allowance. These price changes are typically reductions that the PLCB simply passes on to consumers in the form of monthly sales. The sale prices are available in all stores for 28-day periods beginning on the Monday closest to the end of the month. Distillers can change their wholesale prices in this fashion up to four times a year, or once per quarter, but 
require the board's approval approximately five months before the proposed price reduction. A product can thus go on sale for one month, but not for two in a row. The monthly sales are a useful source of inter-temporal variation in prices that we exploit below in the estimation of our demand model.

\section{Table 2: Characteristics of Spirit Sales}

\begin{tabular}{lrr}
\hline \hline Spirit Type & $\begin{array}{r}\text { Percentage } \\
\text { On Sale }\end{array}$ & $\begin{array}{r}\text { Frequency } \\
\text { Of Sales }\end{array}$ \\
\hline GIN & 61.9 & 3.2 \\
RUM & 79.5 & 3.0 \\
TEQUILA & 82.8 & 3.4 \\
VODKA & 91.2 & 3.0 \\
WHISKEY & 77.8 & 2.9 \\
\hline CHEAP & 79.2 & 3.0 \\
EXPENSIVE & 83.3 & 3.0 \\
ALL PRODUCTS & 81.2 & 3.0 \\
\hline
\end{tabular}

Source: $P L C B$. "Percentage On Sale" is the percentage of products that go on sale at least once in 2005. "Frequency of Sales" is the average number of times a product goes on sale during the year.

Table 2 shows that products are on sale an average of three times a year, just short of the maximum four allowed by the $P L C B$ 's pricing procedures. Sales are not rare events: over $80 \%$ of spirits are on sale at least once in 2005. This is true across spirit types, with vodka and expensive varieties being more frequently on sale than the rest. Table 3 further documents the seasonal pattern of sales across spirit types by tabulating the average share of products on sale in a given spirit category and quarter. For example, $10 \%$ of gins are on-sale in the spring. Spirits are more likely to go on sale during summer and winter.

Table 3: Seasonal Patterns of Spirit Sales

\begin{tabular}{lccccr}
\hline \hline & \multicolumn{5}{c}{ Percent of Products On-Sale } \\
\cline { 2 - 6 } Quarter & GIN & RUM & TEQUILA & VODKA & WHISKEY \\
\hline SPRING & 10.0 & 16.0 & 17.1 & 16.5 & 11.8 \\
SUMMER & 18.3 & 19.5 & 28.4 & 23.5 & 21.4 \\
FALL & 11.7 & 15.1 & 14.8 & 14.7 & 12.1 \\
WINTER & 19.1 & 20.6 & 20.7 & 21.5 & 20.6 \\
\hline YEAR & 15.5 & 17.9 & 20.2 & 19.0 & 16.6 \\
\hline
\end{tabular}

In summary, prices can change at two discrete times per month, either due to a permanent adjustment in the wholesale price at the beginning of a reporting period, or due to a temporary wholesale price adjustment at the end of the month. 
Table 4: Ratio of Retail Prices in State Relative to Pennsylvania

\begin{tabular}{lcccccc}
\hline \hline Spirit Type & ME & MI & NC & OH & VT & VA \\
\hline GIN & 1.00 & 0.97 & 0.91 & 0.96 & 0.95 & 1.05 \\
RUM & 1.02 & 1.02 & 0.96 & 1.03 & 0.98 & 1.10 \\
TEQUILA & 1.05 & 1.10 & 1.05 & 1.05 & 1.09 & 1.12 \\
VODKA & 1.13 & 1.09 & 1.03 & 1.01 & 1.05 & 1.22 \\
WHISKEY & 1.05 & 1.04 & 0.99 & 1.01 & 0.98 & 1.10 \\
\hline ALL PRODUCTS & 1.06 & 1.05 & 1.00 & 1.01 & 1.01 & 1.13 \\
\hline
\end{tabular}

Authors' calculations of non-weighted average ratios using 2005 monthly prices of 250 spirit varieties reported by National Alcohol Beverage Control Association (2005).

How do the price levels documented in Table 1 compare to other states? Despite common beliefs among Pennsylvanians, there is only limited evidence that the PLCB's pricing policies lead to systematically higher prices in Pennsylvania across the full spectrum of products. According to data from the National Alcohol Beverage Control Association (2005), alcohol markups in Pennsylvania are in line with those in other control states, ranging from $17.6 \%$ in the case of Wyoming to $64.5 \%$ in Utah. ${ }^{11}$ We also use data from NABCA to compute the average of the ratio of 2005 prices for 250 spirit varieties in six control states relative to Pennsylvania's. Table 4 shows that Pennsylvania's prices are comparable and frequently somewhat lower than those in the other control states.

\subsection{Evidence of Heterogeneity of Preferences for Liquor}

The premise behind our analysis is that the $P L C B$ could perform better using a less restrictive pricing strategy than a single uniform percent markup across all spirits and geographic markets. If arbitrage is avoidable and segmenting costs not too onerous, charging different markups for different products and individuals will result in a profit increase as pricing is better tailored to consumers' heterogeneous preferences, e.g., Wilson (1993, §5). But, are Pennsylvanians' preferences for alcohol heterogeneous enough to justify such practices? And if that is the case, on what dimensions do they differ?

In Section 3.2 below we describe how we allocate census blocks to each store in order to define the market served by each liquor store and the demographics of their potential

${ }^{11}$ We are unaware of systematic information to compare Pennsylvania's prices to those in the possibly more similar open states in close proximity to Pennsylvania. Data compiled for the ACCRA (2008) cost of living index provides some anecdotal evidence that prices are indeed higher in Pennsylvania: a 1.5 liter bottle of Livingston Cellars retailed for $\$ 7.99$ in Pennsylvania, compared to a median price of $\$ 6.99$ in the sample of 37 cities in neighboring states, with prices in all but one city being below Pennsylvania's. 
Figure 1: Consumption Patterns Across Demographics

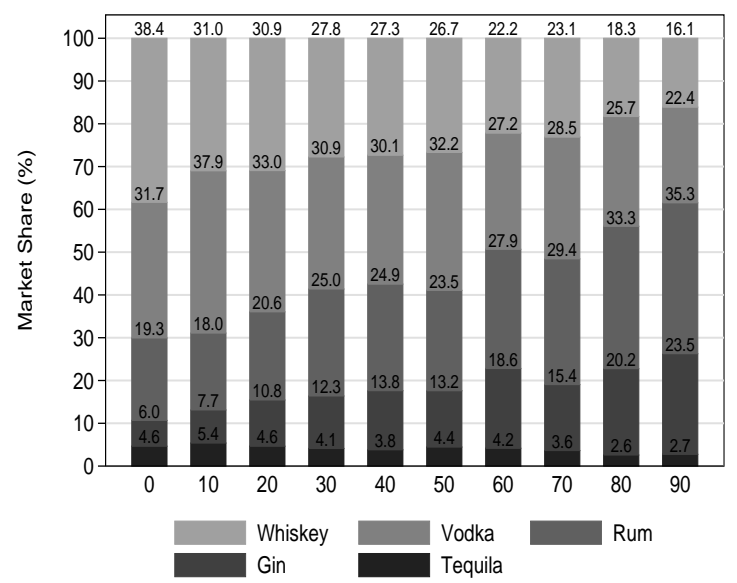

(a) Share of Minority Population

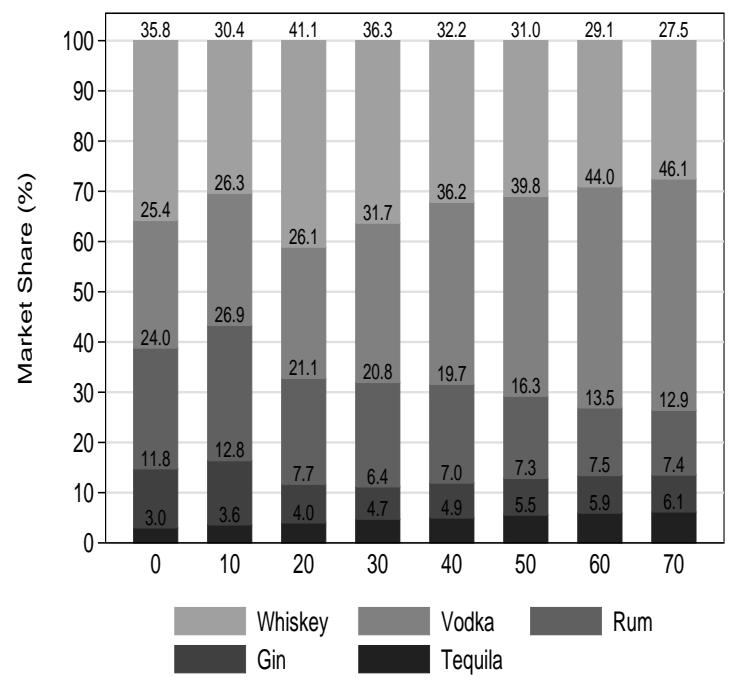

(c) Share of High-Income Population

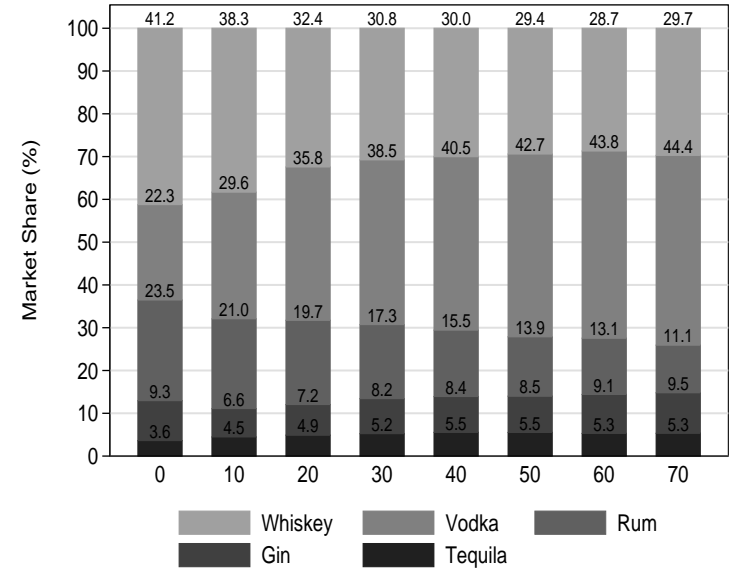

(b) Share of College Educated Population

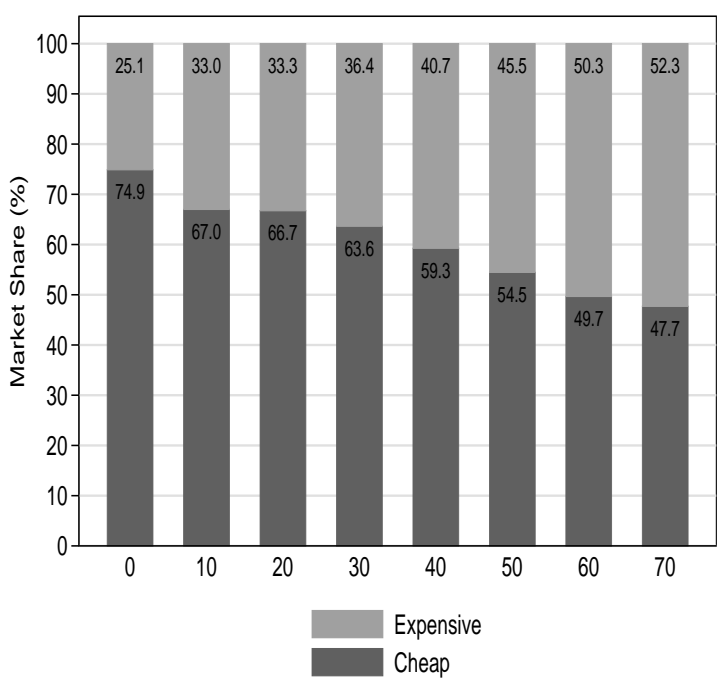

(d) Share of High-Income Population

customers. It is then possible to cross-tabulate spirit consumption with observable market demographics to highlight differentiated consumption patterns. We do so using data from the $P L C B$ on 2005 product-level sales by store aggregated to the spirit type. Figure 1 makes use of this information by ranking markets according to income levels, education, or the presence of minorities.

Results show that consumer preferences for different types of spirits are indeed heterogeneous. Panel (a) in Figure 1 shows the market shares of sales of five categories of spirits as we increase the presence of minorities (i.e., non-white population) in the store market area. It is evident that minorities favor gin and rum over whiskey and vodka. In markets 
where minorities only represent about $10 \%$ of the population, gin reaches $7.7 \%$ of total spirit sales and rum $18.0 \%$. However, in those markets where minorities amount to $90 \%$ of the population the share of gin climbs to $23.5 \%$ and rum to $35.3 \%$. In these same markets, vodka amounts to $22.4 \%$ of spirit sales and whiskey just $16.1 \%$. These shares almost double in predominantly white neighborhoods: the market share of vodka is $37.9 \%$ and whiskey $31.0 \%$ in markets where $90 \%$ of the population is white. Repeating the analysis, Panel (b) shows that college educated consumers strongly favor vodka over any other spirit type, while Panel (c) shows that this preference for vodka is more clearly defined in markets where most potential customers are high income earners with household incomes above $\$ 50,000$.

Table 5: Product Choice Set Comparison: Low and High Income Markets

\begin{tabular}{lrlrrrrr}
\hline \hline & \multicolumn{3}{c}{ Bottom Income Decile } & & \multicolumn{3}{c}{ Top Income Decile } \\
\cline { 2 - 3 } \cline { 7 - 8 } Spirit Type & Products & Price & Share & & Products & Price & Share \\
\hline GIN & 11.88 & 11.68 & 14.50 & & 13.64 & 16.85 & 8.00 \\
RUM & 23.27 & 12.51 & 28.27 & & 24.69 & 12.76 & 14.17 \\
TEQUILA & 9.33 & 20.25 & 3.75 & & 15.18 & 21.85 & 6.43 \\
VODKA & 38.88 & 15.54 & 27.52 & & 48.40 & 16.61 & 43.39 \\
WHISKEY & 38.03 & 14.64 & 25.96 & & 48.83 & 18.12 & 28.01 \\
\hline ALL PRODUCTS & 117.90 & 14.07 & 100.00 & & 148.80 & 16.85 & 100.00 \\
\hline
\end{tabular}

Statistics based on markets with average annual household income either less than $\$ 31,020$ (Bottom) or more than $\$ 74,400$ (Top). "Products" reports the average number of products available in each category. Average price are sales-weighted. "Share" denotes the share of each spirit type based on sales of $750 \mathrm{ml}$ bottles.

Panel (d) in Figure 1 focuses on a different issue: even when they purchase the same type of spirit, high income customers strongly favor more expensive varieties. ${ }^{12}$ Thus, we expect the elasticity of demand for spirits to vary with income. Table 5 characterizes the markets at the top and bottom decile of the income distribution in more detail. Relative to the poorest markets, affluent consumers purchase a substantially larger number of higherpriced spirit products at an almost $\$ 3$ higher average price per bottle. Average prices paid for rum are almost identical across income groups and only $\$ 1$ higher for tequila and vodka, but the difference reaches $\$ 3.50$ for whiskey and exceeds $\$ 5$ for gin, one of the least favored categories among affluent consumers (compare the $8.03 \%$ and $13.38 \%$ market shares to those of most other categories). Table W.4 in the Web Appendix lists the top ten products purchased by customers of these two income segments, suggesting that consumers differ not only in their preferred spirit type, but also in their choices of specific products.

${ }^{12}$ Each product's price relative to the median of the non-weighted price distribution within the spirit type determines whether a product is categorized as CHEAP or EXPENSIVE within its spirit type. 
We conclude that consumer preferences are substantially heterogeneous not only across spirit types, but even within them. It is not only that white and educated customers disproportionately purchase vodka over gin and rum, but also that higher income earners purchase more expensive products across all spirit types. A one-size-fits-all pricing policy cannot fully target such heterogeneity in tastes and is thus going to imply some surplus redistribution across demographic groups. The extent of this redistribution is difficult to assess conclusively using observed consumption patterns and prices only. For example, while currently, there is a gap between markups paid by high and low-income households, this evidence does allow the conclusion that current prices favor low-income households, relative to the prices they would pay under less restrictive pricing rules. This requires, instead, an assessment of different household types' responsiveness to different possible price vectors that can then be used to compare current markup and price differences between consumer segments of interest to those generated by alternative pricing policies. The rest of the paper aims to first quantify preference differences and then perform this comparison.

\section{Demand Estimation}

We want to evaluate potential foregone profits, welfare changes, and the sign and size of the rent redistribution implied by the current uniform pricing strategy. This requires a model of consumer demand that can be used to consistently estimate demand responses to alternative prices. We follow the large literature on discrete-choice demand system estimation using aggregate market share data, e.g., Berry (1994), Berry et al. (1995), and Nevo (2001), in modeling demand for spirits as a function of product characteristics and prices, as well as the distribution of consumer demographics. This facilitates the estimation of own and cross-price elasticities for a large-dimensional set of differentiated products. More importantly, when combined with cost information, it allows us to determine the profit maximizing prices of spirits under alternative pricing rules to the one currently employed by the $P L C B$.

We note upfront that in estimation, we do not use the firm's first-order optimality conditions that are typically relied on to recover marginal costs consistent with the observed prices and profit maximization. The inclusion of these first-order conditions in estimation ensures elastic demand estimates consistent with optimal pricing by a seller with market power. Instead, as we described above, we obtained information on wholesale prices, $c^{w}$, from the $P L C B$ directly. By estimating price responses using the demand side only, we can 
verify ex-post whether our parameter estimates imply elastic demands, in light of the fact that the $P L C B$ 's objective may not be pure profit maximization.

In this section we first briefly describe the standard model of discrete-choice demand estimation of Berry et al. (1995) - BLP hereafter- tailored to the specific features of our setting. We then describe our data, provide details of our estimation approach and discuss the empirical sample variation that allows us to identify the parameters of our model.

\subsection{A Discrete Choice Model of Demand for Spirits}

We specify a consumer's choice between a set of $J_{l t}$ differentiated spirits. At time $t$, consumer $i$ in market $l$ obtains the following indirect utility from consuming spirit $j$ :

$$
\begin{aligned}
& u_{i j l t}=x_{j} \beta_{i}^{*}+\alpha_{i}^{*} p_{j t}+\gamma h_{t}+\xi_{j}+\Delta \xi_{j t}+\zeta_{j l t}+\epsilon_{i j l t}, \\
& \text { where } i=1, \ldots, M_{l} ; \quad j=1, \ldots, J_{l t} ; \quad l=1, \ldots, L ; \quad t=1, \ldots, T .
\end{aligned}
$$

In Equation (1), $x_{j}$ denotes a vector of $n$ observed product characteristics. These are identical in all markets $l$ where the product is available and are fixed over time, although the availability of different spirits changes over time due to new product introductions or product removals or due to the seasonal availability of particular products. In addition $h_{t}$ denotes an indicator of whether period $t$ coincides with the end-of-year holiday season from Thanksgiving to the New Year, while $p_{j t}$ measures product $j$ 's price at time $t$. In accordance with the $P L C B$ 's pricing mandate, the price does not vary across markets $l$. We further include a constant product valuation, $\xi_{j}$, in utility.

We introduce variation in the valuation of product $j$ over time through common state-wide deviations from $\xi_{j}, \Delta \xi_{j t}$, that capture seasonal preferences for different products at different times of the year beyond the demand shifter for holidays. We further include unobserved market demand shocks for product $j$ at time $t$ in market $l, \zeta_{j l t}$. These capture demand drivers such as the product's shelf placement, a store manager's expertise, or local promotion activities, e.g., spirits/wine tastings. We assume that these demand shifters are known to customers at the time of their purchase occasion in period $t$. As we discuss above, wholesale price adjustments take effect with significant delay from when these are agreed upon, approximately five months in the case of product sales. Consequently, we assume that the distillers and the $P L C B$ do not know $\zeta_{j l t}$ at the time when they agree on wholesale 
price changes and manufacturer's promotions. We treat these demand shocks as mean-zero, i.i.d. deviations from the statewide shock, $\Delta \xi_{j t}$. In contrast to $\zeta_{j l t}$, we assume that the latter is reflected in the manufacturers' pricing decisions. Lastly, $\epsilon_{i j l t}$ denotes consumer $i$ 's unobserved preferences for product $j$, which we assume to be distributed Type-I extreme value across all products $J_{l t}$.

To allow for individual heterogeneity in response to spirit prices and characteristics, we model the distribution of consumer preferences over characteristics and prices as multivariate normal with a mean that shifts with consumer attributes:

$$
\left(\begin{array}{c}
\alpha_{i}^{*} \\
\beta_{i}^{*}
\end{array}\right)=\left(\begin{array}{c}
\alpha \\
\beta
\end{array}\right)+\Pi D_{i l}+\Sigma \nu_{i l}, \quad \nu_{i l} \sim N\left(0, I_{n+1}\right) .
$$

Consumer $i$ in market $l$ is characterized by one unobserved and a $d$ vector of observed demographic attributes, $D_{i l}$ and $\nu_{i l}$. $\Pi$ is a $(n+1) \times d$ matrix of coefficients that measures the effect of observable individual attributes on the consumer valuation of spirit characteristics, while $\Sigma$ measures the covariance in unobserved preferences across characteristics. Allowing for the resulting random coefficients generates correlations in utilities for the various product alternatives, thus relaxing the restrictive substitution patterns generated by the Independence of Irrelevant Alternatives (IIA) property of the logit model.

Because of the aggregate, store-level nature of our data, we make the common assumption that during a particular time period, each consumer selects either one $750 \mathrm{ml}$ bottle of the $J_{l t}$ spirits available in her market, or opts not to purchase any spirit for off-premise consumption, i.e., chooses the outside option denoted by $j=0$ with zero mean utility. ${ }^{13}$ We define the set of individual-specific characteristics leading to the optimal choice of spirit $j$ as:

$$
A_{j t}\left(x ., p_{\cdot t}, \xi_{\cdot t} ; \theta\right)=\left\{\left(D_{i l}, \nu_{i l}, \epsilon_{\cdot l t}\right) \mid u_{i j l t} \geq u_{i k l t} \quad \forall k=0,1, \ldots, J_{l t}\right\}
$$

13 Nevo (2000, p.401) discusses the potential limitations of the present discrete choice approach with aggregate market data when in practice individuals purchase several products in a single store visit or at different consumption spells within a pricing period. Using the same data set as in this paper, Seim and Waldfogel (2013) present suggestive evidence that the aggregate demand for alcoholic beverages does not respond to price declines more strongly than average for stores that serve a dispersed population with higher distances and travel costs to the store and whose customers have a higher incentive to buy larger quantities or assortments. If such consumer behavior were important, Hendel (1999) shows that assuming single-unit purchases could understate the own and cross-price elasticities of demand in the case of assortment decisions, but overstate own-price elasticities in the case of stockpiling as in Hendel and Nevo (2006). In our data, we find no evidence of stockpiling on aggregate or within markets of similar income. 
summarizing all model parameters by $\theta$. We follow the literature in decomposing the deterministic portion of the consumer's indirect utility into a common part shared across consumers, $\delta_{j l t}$, and an idiosyncratic component, $\mu_{i j l t}$. These mean utilities of choosing product $j$ and the idiosyncratic deviations around them are given by:

$$
\begin{aligned}
\delta_{j l t} & =x_{j} \beta+\gamma h_{t}+\alpha p_{j t}+\xi_{j}+\Delta \xi_{j t}+\zeta_{j l t}, \\
\mu_{i j l t} & =\left(\begin{array}{ll}
x_{j} & p_{j t}
\end{array}\right)\left(\Pi D_{i l}+\Sigma \nu_{i l}\right)
\end{aligned}
$$

In estimating the model, we take advantage of the additive specification of normallydistributed deviations from mean utility and extreme-value random shocks to integrate over the distribution of $\epsilon_{i t}$ giving rise to $A_{j t}$ analytically. The probability that consumer $i$ purchases product $j$ in market $l$ in period $t$ is then given by:

$$
s_{i j l t}=\frac{\exp \left(\delta_{j l t}+\mu_{i j l t}\right)}{1+\sum_{k \in J_{l t}} \exp \left(\delta_{k l t}+\mu_{i k l t}\right)} .
$$

Deriving product $j$ 's aggregate market share in each location requires integrating over the distributions of observable and unobservable consumer attributes $D_{i l}$ and $\nu_{i l}$, which we denote by $P_{D}\left(D_{i}\right)$ and $P_{\nu}\left(\nu_{i}\right)$, respectively. Thus, the model predicts a market share for product $j$ in market $l$ at time $t$ of:

$$
s_{j l t}=\int_{\nu_{l}} \int_{D_{l}} s_{i j l t} d P_{D}\left(D_{i}\right) d P_{\nu}\left(\nu_{i}\right) .
$$

\subsection{Data Description}

We obtained a store-level panel data set from the $P L C B$ under the Pennsylvania Rightto-Know Law. The data contain daily information on quantities sold and gross receipts at the product and store level, together with each product's wholesale price, during 2005. We complement the $P L C B$ data with detailed information on the distribution of representative demographic attributes obtained from the Census Bureau to evaluate the effect of demographics on spirit purchase decisions in the absence of individual purchase information.

We aggregate the data over days on which the wholesale price, and consequently the retail price, remains constant because they share both the same reporting period and the 
same sales period, as discussed in Section 2. This periodicity of on average 14 days accounts for the strong seasonality inherent in liquor sales, which are disguised in more aggregate definitions. $^{14}$

We focus our analysis on sales of $750 \mathrm{ml}$ bottles of spirit products. Spirits make up a smaller, better-defined group of products than wines, thus limiting the size of the consumer's choice set to a manageable number of products with non-negligible market shares. Furthermore, unlike wines, which are critically defined by the uniqueness of their vintage, spirits are more standardized, are marketed over a longer time horizon, and can be described by easily measurable product characteristics, such as the type of spirit, the alcohol content, or whether or not a fruit or other flavor is added. We consider five types of spirits: gin, rum, tequila, vodka, and whiskey.

We also collected information on five product characteristics: the spirit's type (gin, rum, tequila, vodka, or whiskey), the alcohol content, an indicator for flavor add-ons, an indicator for whether the product is imported, and a quality measure in the form of an index of experts' product ratings. ${ }^{15}$ Table 6 summarizes these product characteristics by type of spirit for the 233 products that are sold in at least one time period in 2005. The sales-weighted average alcohol content (proof) is $81 \% ; 44 \%$ of product sales are for imported products; and $14 \%$ of spirits contain flavor add-ins. Flavored products are primarily rums and vodkas. While $100 \%$ of tequilas are imported, foreign produced spirits make up roughly over $40 \%$ of gins and rums, $30 \%$ of whiskeys, and almost $50 \%$ of vodkas. We further report the average quality score of the spirits in the sample; gins and tequilas are clearly above the average while rums are, in general, of lower quality.

Within spirits, vodkas and whiskeys have significantly larger market shares, $35 \%$ and $31 \%$, respectively, than rum at $21 \%$ or gin and tequila, which account for $8 \%$ and $5 \%$ of sales, respectively. The differences in product variety within each category mirror the differences in market shares, with only approximately one third as many gin and tequila varieties as vodka and whiskey varieties. We also see that imports predominate among expensive and higher quality spirits.

${ }^{14}$ We dropped a number of periods that only last a couple of days due to a misalignment of reporting and sales periods. This results in 20 pricing periods that span 2005.

${ }^{15}$ We obtained the product scores from http://www.proof66.com/, last accessed on March 15, 2013. We re-scaled the scores to 0 (lowest quality) to one hundred (highest quality). 
Table 6: Product Characteristics by Spirit Type

\begin{tabular}{lrrrrrrr}
\hline \hline Spirit Type & $\begin{array}{r}\text { Number of } \\
\text { Products }\end{array}$ & $\begin{array}{r}\text { Market } \\
\text { Share }\end{array}$ & Price & Proof & Flavored & Imported & $\begin{array}{r}\text { Product } \\
\text { Quality }\end{array}$ \\
\hline GIN & 20 & 8.44 & 14.32 & 84.93 & 0.00 & 41.13 & 64.02 \\
RUM & 44 & 20.62 & 12.35 & 79.37 & 18.33 & 44.43 & 39.99 \\
TEQUILA & 29 & 5.13 & 20.77 & 79.86 & 1.43 & 100.00 & 58.45 \\
VODKA & 68 & 34.97 & 15.71 & 80.53 & 29.57 & 47.98 & 52.02 \\
WHISKEY & 72 & 30.83 & 15.72 & 81.50 & 0.00 & 30.52 & 53.01 \\
\hline CHEAP & 120 & 59.35 & 11.33 & 79.69 & 13.07 & 27.22 & 49.72 \\
EXPENSIVE & 113 & 40.65 & 20.75 & 82.74 & 15.84 & 68.40 & 53.33 \\
ALL PRODUCTS & 233 & 100.00 & 15.16 & 80.93 & 14.19 & 43.96 & 51.19 \\
\hline
\end{tabular}

"Market Share" is defined relative to total spirit sales (750ml bottles). "Flavored" and "Imported" are reported as percentages. "Quality" refers to the product quality score.

Stores differ somewhat in the product composition of purchases. In part, this is driven by differences in store size: the $P L C B$ operates 65 larger premium stores that carry a wider variety of products, particularly premium wine, than the remaining locations. Primarily, however, these differences in sales composition reflect heterogeneity in consumer preferences rather than differences in the availability of products across stores. Absent store-level inventory information, we treat a product as being available in a store if it sold at least once during a given time period. Of the top 100 bestselling products statewide in 2005, the median store carried $98 \%$, while a store at the fifth percentile carried $72 \%$ of the products. ${ }^{16}$

3.2.1 Store Markets and Market Size. We define the geographic area a particular PLCB store serves in a given time period by mapping each PA census block group (with an average population of 1,186$)$ to its closest store based on the straight line distance from the block group's population-weighted centroid to each $P L C B$ store open in that period. ${ }^{17}$ We then aggregate across block groups to derive each store's population served in that period. ${ }^{18}$ This

${ }^{16}$ We investigated whether our demand estimates are sensitive to the inclusion of market-specific demand shifters, such as whether the product is sold in a premium store and/or in a store close to Pennsylvania's border with another state, but find no significant qualitative or quantitative differences. For details, see Appendix B for our robustness checks.

17 The assumption that consumers frequent the closest store allows us to abstract from the consumer's store choice problem in estimating demand, focusing instead on the consumer's choice between different spirit varieties available at the chosen store. In making this assumption, we follow previous studies using scanner data such as Chintagunta and Singh (2003).

${ }^{18}$ We combine sales and market areas of stores that operate within the same ZIP code to avoid noisy sales variations across stores that belong to demographically homogeneous markets. The 123 instances of relevance include both store relocations, where a store moved from one location in a ZIP code to another during 2005, but the data contain separate records for the store in the two locations, and instances where the 
results in a maximum of 484 store catchment areas that we consider as separate markets. In some periods, we have fewer markets due to store closures and openings, in which case we reassign the population to the next closest store. The average market contains a population of 29,441, but market size is dispersed with a standard deviation of 17,709. Putting all of this together, our estimation uses a total of 9,530 store-time period pairs (markets) and 1,104,204 product-store-time period observations.

The relevant product market includes all distilled spirit purchases consumers make for on- or off-premise consumption. According to Adams Liquor Handbook (2004), average Pennsylvania per-capita sales of distilled spirits amount to 5.16 750-ml bottles annually. In constructing the total market size $M_{l}$, we assume that every person of drinking age consumes the equivalent daily consumption rate of of 0.01 bottles for the number of days in each time period and scale per-capita consumption by the number of people in each market. ${ }^{19}$

3.2.2 Demographic Heterogeneity. In the absence of individual-level information on the demographic attributes of consumers, we follow BLP and use the population distribution of demographic attributes for each of our markets, aggregating across block groups to the store market. Table 7 reports the distribution across markets of the demographic indicators considered in our econometric analyses: household income, educational attainment, age, and whether the head of household is non-white, respectively. Our markets are very heterogeneous along all demographic categories considered. Table W.1 in the Web Appendix shows that these demographics are sometimes highly correlated. For instance, education and income move together, income is lower for minorities and younger individuals, and minorities and older individuals are likely to live in large markets.

To implement the econometric demand model laid out above, we generate a pseudosample of heterogeneous consumers drawing from each market's demographic attribute distributions. In the case of income, we fit continuous market-specific distributions to the discrete distributions of income available from the Census and generate income draws from these fitted distributions. Table $\mathrm{W} .2$ in the Web Appendix provides the descriptive statistics for the parameter estimates of the generalized beta distribution of the second kind that

$P L C B$ operates two stores simultaneously within a ZIP. In addition we drop wholesale stores, administrative locations, and stores without valid address information, or a total of 15 stores.

19 Our results are robust to allowing market size to vary over the course of the year in accordance with the seasonal patterns in $P L C B$ sales. 


\section{Table 7: Demographic Attributes of Markets}

\begin{tabular}{lrrrrr}
\hline \hline & & \multicolumn{4}{c}{ Percentage of Population } \\
\cline { 3 - 6 } Statistic & POPUlation & MINORITy & AGE $\geq 45$ YRS & HIGH INCOME & EDUC $\geq$ COLlEGE \\
\hline MEAN & $29,440.9$ & 12.3 & 39.1 & 39.2 & 24.4 \\
SD & $17,708.5$ & 18.0 & 5.0 & 12.7 & 13.8 \\
MAX & $111,964.0$ & 98.9 & 52.2 & 72.0 & 72.7 \\
Min & $2,574.0$ & 0.2 & 16.5 & 9.4 & 3.0 \\
\hline
\end{tabular}

Source: 2000 Census of Population. MINORITY defined as share of non-white population. Income represents household income and HIGH INCOME defined as household income greater than $\$ 50,000$. EDUC $\geq$ COLLEGE refers to the population with at least a four-year college education. AGE $\geq$ 45 YRS refers to the share of population greater than 44 years of age. Surveys indicate a steady decline in alcohol use once consumers reach 45 years of age. See U.S. Department of Health and Human Services (2010). $n=484$ markets.

we employ. ${ }^{20}$ To address education and minority status we simulate agents by drawing from a uniform distribution with market specific cutoffs defined by the percentage of college educated and minority residents, respectively.

\subsection{Estimation Strategy}

We estimate the parameters of the model following the approaches put forward by $B L P$, Nevo (2000) and Nevo (2001). We employ a generalized method of moments estimator (GMM) by interacting the structural demand side error with instrumental variables that control for possibly endogenous prices. In contrast to the settings typically considered in the literature, the $P L C B$ sets uniform percent markups for all products across Pennsylvania irrespective of local demand responses or seasonal changes in demand. The agency's pricing behavior itself thus does not give rise to the typical endogeneity concerns based on the strategic price setting behavior of firms. At the same time, though, the $P L C B$ 's approved prices simply add a fixed markup to the prices set by distillers. This opens the possibility that spirit prices are endogenous not because of the pricing practices of the $P L C B$ but because of the profit maximizing behavior of distillers whose negotiated wholesale prices may reflect the effect of unobserved product characteristics.

We define the demand error term $\Delta \xi_{j t}$, the unobserved common valuation shock for product $j$ in period $t$, as a function of the data and the values of the coefficient param-

20 The generalized beta distribution has been shown to provide a good fit to empirical income data relative to other parametric distributions. See McDonald (1984). 
eters under consideration. To derive the error term, we first find the mean-utility levels $\delta_{. l t}\left(x ., p_{\cdot t}, h_{t}, S_{\cdot l t} ; \theta\right)$ that set the predicted market share of each product, $s_{j l t}$ in Equation (6), equal to the market share observed in the data, $S_{j l t}$. The mean utility level $\delta_{\text {.lt }}$ is the solution to the implicit system of equations:

$$
s_{\cdot l t}\left(x ., p_{\cdot t}, \delta_{. l t} ; \theta\right)=S_{. l t},
$$

which we solve numerically for every candidate parameter vector and every market $l$ and time $t$. We then project the resulting estimate of $\delta_{\cdot l t}$ onto prices and characteristics to result in our estimate of $\Delta \xi_{\cdot t^{2}}{ }^{21}$

$$
\Delta \xi_{j t}(\theta)=\frac{1}{L} \sum_{l=1}^{L}\left[\delta_{j l t}\left(x ., p_{\cdot t}, h_{t}, S_{\cdot l t} ; \theta\right)-x_{j} \beta-\alpha p_{j t}-\xi_{j}\right]
$$

The GMM estimator exploits the fact that at the true value of parameters $\theta^{\star}$, the instruments $Z$ are orthogonal to the errors $\Delta \xi\left(\theta^{\star}\right)$, i.e., $E\left[Z^{\prime} \Delta \xi\left(\theta^{\star}\right)\right]=0$, so that the $G M M$ estimates solve:

$$
\hat{\theta}=\underset{\theta}{\operatorname{argmin}} \Delta \xi(\theta)^{\prime} Z W Z^{\prime} \Delta \xi(\theta),
$$

where $W$ is a weighting matrix and we loop through every market-time period combination to define the objective function. ${ }^{22}$ Since the effect of product characteristics $x_{j}$ cannot be identified separately from the constant product valuation, $\xi_{j}$, we employ product fixed effects in the GMM estimation and project the estimated fixed effects on the observable product characteristics in a second stage. Appendix A describes the estimation algorithm in further detail.

3.3.1 Instruments. The structural error term in Equation (8) represents the unobserved deviation from the mean product fixed effect. As discussed above, we assume that distillers observe this deviation in the product's demand and account for it when negotiating the price of their products with the $P L C B$. At the same time, the uniform, state-wide pricing mandate of the $P L C B$ limits the ability or willingness of distillers to change wholesale prices based on the change in product valuation in a particular regional sub-market of Pennsylvania.

\footnotetext{
21 Note that we assume that individual locations have mean zero i.i.d. unobserved product shocks.

${ }^{22}$ In constructing our optimal weighting matrix, we first assume homoscedastic errors and use $W=$ $\left[Z^{\prime} Z\right]^{-1}$ to derive initial parameter estimate. We then relax this assumption and use $E\left[Z^{\prime} \Delta \xi \Delta \xi^{\prime} Z\right]^{-1}$ as a consistent estimate for $W$.
} 
Therefore, we control only for unobserved (to the econometrician) changes in statewide product valuations across time, modifying the approach in Nevo (2000) and Nevo (2001) to account for the uniform percent markup rule across stores in Pennsylvania. We employ the average retail prices of nearby control states in each period as instruments for Pennsylvania's price (i.e., 20 instruments). Our underlying identifying assumption is that controlling for spirit-specific characteristics and observable demographics, valuations are independent across states, but correlated within a state. Other states' retail prices are correlated to the common marginal costs of distillers that serve all states, but are uncorrelated with state-specific seasonal variations in valuations due to the independence assumption.

3.3.2 Parameter Identification. Identification of individual preferences results from observing consumer behavior over time and across markets. A product's own-price elasticity is identified by variation in prices over time and by variation in the choice set, both across time and across stores. Wholesale prices are identical across stores, but vary over time as distillers put their products on sale or as wholesale prices change. The fact that the $P L C B$ does not change the prices of all spirits or of all products within a particular spirit type at the same time introduces variation in relative prices over time, which is most useful for the identification of cross-price elasticities. Figure W.1 in the Web Appendix shows how the relative prices of a select group of spirits vary over the 2005 sample.

The preferences for product characteristics and for spirit types are identified by variation in product characteristics that correlates with differences in market shares of spirits by attribute, spirit type, and by the overall size of the category over time. Individual heterogeneity in such preferences is identified by the cross-market heterogeneity in the distribution of demographics. As we document in Section 2.2, different socioeconomic groups have markedly varied preferences across spirit types and quality within each spirit type.

\section{Estimation Results}

Table 8 presents three sets of demand estimates. Specification (1) shows ordinary least squares results of a regression of the logarithm of the ratio of each product's share to the outside share. Specification (2) uses the same dependent variable, but instruments for price using the prices in other control states as discussed above. Each IV is significant at the $95 \%$ 
Table 8: Demand Estimates

\begin{tabular}{|c|c|c|c|c|c|c|c|}
\hline Mean Utility $(\alpha, \beta)$ & \multicolumn{2}{|l|}{ OLS } & \multicolumn{3}{|c|}{ IV } & \multicolumn{2}{|l|}{ Full Model } \\
\hline PRICE & $-0.1576(0.0094)$ & $* * *$ & -0.2056 & $(0.0183)$ & $* * *$ & $-0.1813(0.0088)$ & $* * *$ \\
\hline HOLIDAY & $0.5807(0.0135)$ & $* * *$ & 0.5798 & $(0.0140)$ & $* * *$ & $1.0944(0.0884)$ & $* * *$ \\
\hline CONSTANT & $-8.8880(0.5082)$ & $* * *$ & -9.1439 & $(0.6687)$ & $* * *$ & $-6.3235(0.2828)$ & $* * *$ \\
\hline PROOF & $2.3658(0.4796)$ & $* * *$ & 2.8882 & $(0.6388)$ & $* * *$ & $0.8553(0.2817)$ & $* * *$ \\
\hline QUALITY & $0.3380(0.0706)$ & $* * *$ & 0.4301 & $(0.0908)$ & $* * *$ & $0.0643(0.0285)$ & $* * *$ \\
\hline FLAVORED & $-0.6124(0.1631)$ & $* * *$ & -0.6794 & $(0.1986)$ & $* * *$ & $-0.4982(0.0726)$ & $* * *$ \\
\hline IMPORTED & $0.8712(0.1347)$ & $* * *$ & 1.1753 & $(0.1655)$ & $* * *$ & $0.1158(0.0632)$ & $*$ \\
\hline GIN & $-0.7713(0.2626)$ & $* * *$ & -0.9568 & $(0.3117)$ & $* * *$ & $-0.0960(0.0951)$ & \\
\hline RUM & $0.1921(0.1963)$ & & 0.1777 & $(0.2426)$ & $* * *$ & $0.2750(0.0851)$ & $* * *$ \\
\hline TEQUILA & $0.7283(0.3568)$ & $* *$ & 1.0983 & $(0.4615)$ & $* *$ & $-0.2726(0.1060)$ & $* * *$ \\
\hline VODKA & $0.3978(0.2088)$ & $*$ & 0.4148 & $(0.2547)$ & & $0.4226(0.0718)$ & $* * *$ \\
\hline \multicolumn{8}{|l|}{ Standard Dev. $(\sigma)$} \\
\hline PRICE & & & & & & $0.0015(0.1145)$ & \\
\hline CONSTANT & & & & & & $0.0138(0.1738)$ & \\
\hline \multicolumn{8}{|l|}{ Interactions (П) } \\
\hline INCOME & & & & & & $2.2958(0.1166)$ & $* * *$ \\
\hline PRICE $\times$ INCOME & & & & & & $-0.0487(0.0190)$ & $* * *$ \\
\hline EDUCATION & & & & & & $-3.6162(0.1610)$ & $* * *$ \\
\hline MINORITY & & & & & & $-0.7471(0.1648)$ & $* * *$ \\
\hline \multicolumn{8}{|l|}{ Elasticity Statistics: } \\
\hline Average & -2.54 & & -3.31 & & & -3.32 & \\
\hline Sales-weighted Avg. & -2.38 & & -3.10 & & & -3.11 & \\
\hline Percentage Inelastic & 1.94 & & 0.00 & & & 0.02 & \\
\hline Off-Premise Spirit Demand & -2.05 & & -2.67 & & & -1.86 & \\
\hline \multicolumn{8}{|l|}{ First Stage: } \\
\hline$F-$ Statistic & & & 20.418 & & & & \\
\hline Percentage Significant & & & 100.0 & & & & \\
\hline$\overline{R^{2}}$ & 0.982 & & 0.982 & & & & \\
\hline Minimum Distance $\chi^{2}(\mathrm{df})$ & & & & & & $79.0(13)$ & \\
\hline Observations & $1,104,204$ & & $1,104,204$ & & & $1,104,204$ & \\
\hline Markets & 9,530 & & 9,530 & & & 9,530 & \\
\hline Agents per Market & & & & & & 100 & \\
\hline
\end{tabular}

Robust standard errors are reported in parentheses with p-values denoted by ${ }^{*} p<0.10$, ${ }^{* *} p<0.05$, and ${ }^{* * *} p<0.01$. All mean utility estimates $(\alpha, \beta)$ except PRICE and HOLIDAY are obtained by minimum distance, second-stage regression of product fixed effects on spirit characteristics. "Off-Premise Spirit Demand" is the price elasticity of total PLCB spirit sales (750ml bottles).

level and the set of IVs generates a F-statistic of 20.4 indicating the set is also significant. Our main specification in column 3 adds interactions allowing for the baseline taste to shift with income, educational attainment, and minority status and the price responsiveness to 
vary with income. All specifications include product fixed effects that we then, as described above, project on the product characteristics in Table 6 in a second stage.

The demand estimates are stable across specifications. The price coefficient drops slightly as we employ instrumental variables techniques, suggesting that distillers base their pricing decisions to some degree on variation in demand not captured by observables in the data. Preferences for spirit purchases rise significantly during the holiday period, which we define to be periods that overlap with Christmas or Thanksgiving. Consumers have a preference for un-flavored and imported varieties and utility increases in the product's alcohol content and quality. Conditional on these characteristics, they prefer vodkas and rums to whiskeys, the left-out category, but prefer whiskeys to tequila.

Estimates of the interaction parameters $\Pi$ reveal that consumption of the outside good is increasing in both education and minority status, but decreasing in income. Further, demand shifts outwards and becomes flatter as the income of households increases. Thus, demand elasticities might increase or decrease depending on which of these two effects dominates at the observed prices. This ambiguity is interesting because theory does not suggest restrictions for the sign of the relationship between demand elasticity and income. In some environments, it is natural to expect that the smaller the share of income the consumption of a particular product represents, the less elastic demand should be. In our case, we estimate that the average household spends only $\$ 28.25$ annually on spirits at $P L C B$ stores (i.e., on "off-premise" consumption) and we might thus expect demand for spirits among higher income households to be less elastic than for low income households. Our results suggest instead that at current prices, there is a small, but negative effect of income on the demand elasticity of spirits. We argue that our results reflect an additional factor that dominates the income-price elasticity of demand relationship: the variety available and the closeness of substitutes. Demand for spirits among higher income households is more elastic because there are more products available in the high-quality product segments that they typically favor (see, e.g., Table 5). Furthermore, they can also substitute to lower-quality products rather than just to the outside option.

The income gradient of the price elasticity is small, however: at an aggregate level, the price elasticity of off-premise spirit demand is -1.57 for markets with average household income in the lowest income quartile, compared to -2.01 for markets in the fourth income quartile, and -1.86 overall. This is comparable to estimates in the literature: in a review, Leung and Phelps (1993) conclude that, based on 15 studies analyzing aggregate data on 
Figure 2: Distribution of Demand Elasticities

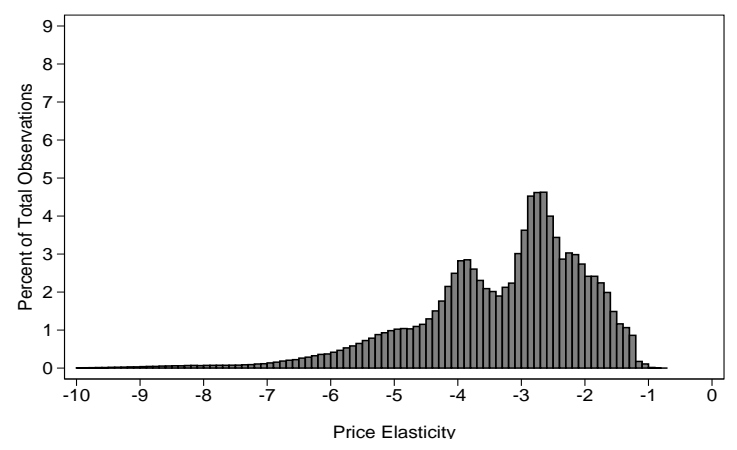

(a) All Spirits

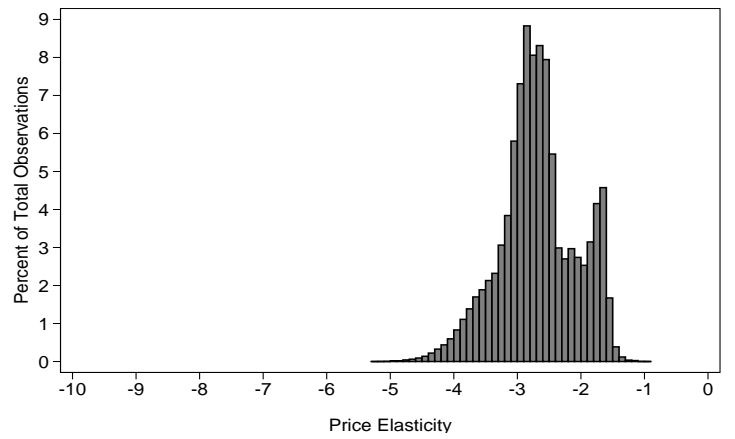

(c) Rum

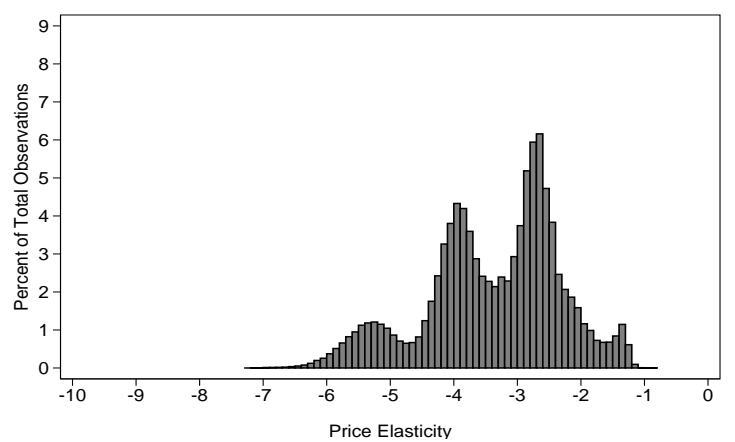

(e) Vodka

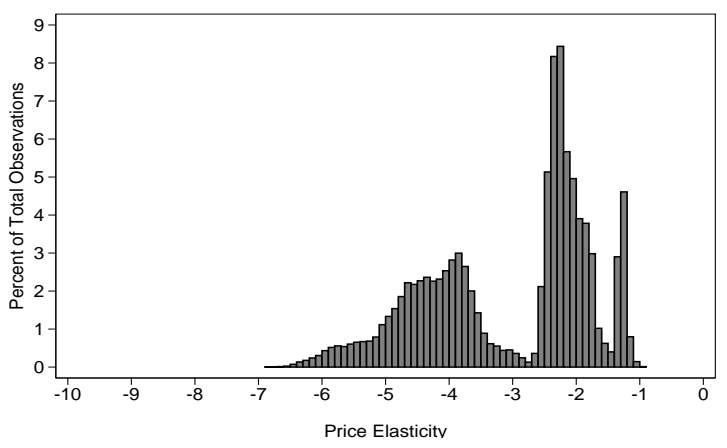

(b) Gin

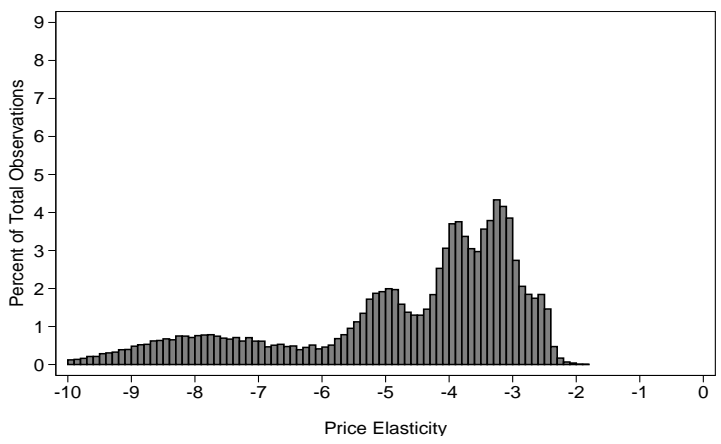

(d) Tequila

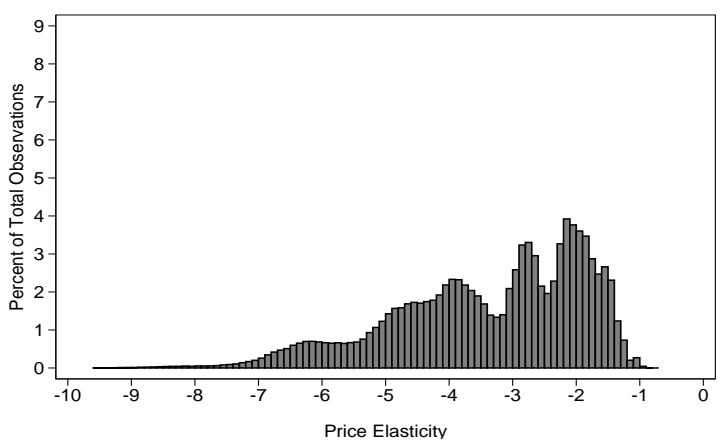

(f) Whiskey

alcohol consumption, the price elasticity of demand for distilled spirits is -1.5 . At the product-level, we estimate an average own-price elasticity of -3.32 . Comparable productlevel elasticities for spirit products are rarely available in the literature, in part because spirits are not commonly carried in grocery stores, the most reliable source of scanner data. ${ }^{23}$

${ }^{23}$ For instance, in analyzing a distilled spirits merger, Ashenfelter and Hosken (2010), for example, have to rely on a ten-city sample of California drug stores and do not find consistently negative quantity adjustments in response to post-merger price increases. 
The results in Table 9 and Figure 2 encapsulate the driving forces explaining the result of our counterfactuals in Section 5. For a uniform 30\% markup to be optimal across all products sold by the $P L C B$, demand elasticity estimates should be roughly identical for all spirits. This is not the case. For instance, demand for vodka products is significantly more elastic than for rum products. Yet, all spirits are sold with a common $30 \%$ markup, which suggests that vodkas are overpriced in relative terms, and that there is overconsumption of rum relative to consumption under a profit-maximizing multi-product monopoly pricing strategy (fixing average price levels). The current one-size-fits-all policy thus necessarily benefits different consumer groups differentially: rents are transferred from consumers of vodkas to consumers of rum.

Table 9: Price Elasticities by Spirit Type

\begin{tabular}{lrrrrrr}
\hline \hline Spirit Type & Price & Elast & Median & P25 & P75 & SD \\
\hline GIN & 14.5 & -2.9 & -2.3 & -4.2 & -2.0 & 1.3 \\
RUM & 12.5 & -2.6 & -2.6 & -2.8 & -2.2 & 0.6 \\
TEQUILA & 21.0 & -4.2 & -3.9 & -4.2 & -3.5 & 1.3 \\
VODKA & 16.1 & -3.3 & -3.0 & -4.0 & -2.5 & 1.1 \\
WHISKEY & 15.9 & -3.2 & -2.9 & -4.1 & -2.1 & 1.3 \\
\hline CHEAP & 11.4 & -2.3 & -2.4 & -2.7 & -1.9 & 0.6 \\
EXPENSIVE & 20.5 & -4.1 & -4.0 & -4.6 & -3.5 & 1.0 \\
ALL PRODUCTS & 15.4 & -3.1 & -2.8 & -3.9 & -2.3 & 1.2 \\
\hline
\end{tabular}

"Price" is measured in dollars; "Elast" reports the sales-weighted average elasticity for each spirit category; "P25" and "P75" reports the lower and upper quartile of the empirical distribution of elasticities; and "SD" is the corresponding standard deviation.

The heterogeneity of demand elasticities is not present only across spirit types, but also within them. Thus, for instance, vodkas and rums are more similar at the less elastic segments (p75) than at the more elastic ones (p25). The empirical distribution of price elasticities is most spread for whiskeys and gins while most concentrated for rums. Notice also that Figure 2 depicts multi-modal distributions of elasticities for all five spirit types. Spirit types are thus further segmented into higher and lower quality with different responses to price changes. The bottom of Table 9 corroborates this hypothesis. The demand for the most expensive products is more elastic than the demand for cheap spirits. Consumers of expensive products have closer substitutes including more variety in high-end segments, e.g., Table 5, as well as cheap spirits, which are closer substitutes than off-premise consumption. Buyers of cheap spirits only contemplate the latter alternative, thus leading to less elastic demand for inexpensive spirits. 


\section{Welfare Consequences of Non-Uniform Markups}

With robust estimates of spirit demand in hand, we are in a position to address the economic consequences of the $P L C B$ 's choice to refrain from using more flexible pricing strategies As discussed in the Introduction, it is theoretically ambiguous whether price discrimination, such as $3 D P D$ is more or less efficient than uniform pricing. In this section we compare alternative, more flexible, non-uniform markup strategies accounting for the nonlinearities of individual market demands that have hindered general comparisons since the work of Robinson (1933). Furthermore, we address these questions in the context of a meaningful economic application where we evaluate the possibility of improving upon the current uniform percent markup policy of the $P L C B$.

We employ our estimates from Table 8 as the complete characterization of Pennsylvania demand for spirit products. We first use these estimates and the distributions of demographics within and across markets to compute optimal prices under increasingly more complex pricing strategies, assuming that the $P L C B$ chooses them to maximize profits. Based on the resulting price vectors, we rely on the estimated model and the $P L C B$ 's wholesale cost information to compute demand for each spirit, markups, and profits, as well as consumer surplus. A comparison of these measures allows us to determine how different the $P L C B$ 's pricing is from variants of a multi-product monopolist's pricing in terms of profitability and efficiency. Next, we relate the changes in these economic outcomes to socioeconomic variables in order to uncover the implicit redistribution of rents - or cross-subsidization - among Pennsylvanians, as induced by the PLCB's uniform percent markup pricing rule.

\subsection{Counterfactual Analysis: Procedure}

Consider a multi-product, profit-maximizing monopolist's pricing problem in several $l$ geographical markets and time periods $t$, i.e., the monopolist can set different prices not only in different time periods (as implicitly done by the $P L C B$ currently), but potentially also in different local markets. For each time period and each market, the firm chooses a vector of prices $\left\{p_{. l t}\right\}$ to solve:

$$
\max _{\left\{p_{. l t}\right\}} \sum_{j \in J_{l t}}\left(p_{j l t}-c_{j t}^{w}\right) M_{l} s_{j l t}\left(p_{. l t}\right)
$$


where $s_{j l t}(p)$ is the market share of product $j$ in market $l$ in period $t$ conditional on prices $p_{. l t}$ and given market size $M_{l}$ and $c_{j}^{w}$, the wholesale price of a bottle of product $j$.

We consider two alternative pricing strategies that place the following constraints on the firm's objective function in Equation (10):

$$
\begin{aligned}
& p_{j l t}=\left[(1+\lambda) c_{j t}^{w}+\$ 1.20\right] \times 1.18 \quad \forall l, \\
& p_{j l t}=p_{j t} \quad \forall l
\end{aligned}
$$

Under constraint (11a), the firm chooses a single uniform markup percentage $\lambda$, which maximizes (10). We call this the "Uniform П-Maximizing Markup" counterfactual, which aims at evaluating whether the current 30\% markup policy is close to maximizing profits within the set of single uniform markup rules. To make the markup percentage $\lambda$ comparable to the current policy, we maintain the bottle fee of $\$ 1.20$ and liquor tax of 18\%. Under constraint (11b), the firm maximizes (10) by choosing product-specific prices that apply uniformly across the state in a given period. We call this the "Product-Specific" counterfactual, which is interesting to evaluate for two reasons. First, markups are allowed to differ across spirits, but retail prices continue to be the same across local markets. This avoids any possible arbitrage of consumers being able to benefit from arbitrage across local markets with different prices for the same product. Second, solving this problem is a substantially simpler pricing strategy than the unconstrained optimal pricing problem; it involves finding at most 233 prices for every time period. In comparison, the unconstrained problem involves finding a vector of 55,210 optimal prices across the 484 markets per time period (or a total of 1,104,204 prices across periods). Lastly, and only for reference, we consider the hypothetical case of fully unconstrained pricing as the most general pricing strategy. We denote the solution to the pricing problem in Equation (10) "3rd Degree Price Discrimination." Ignoring the possibility of arbitrage, it generates the largest profit level possible for the multi-product monopolist as it tailors prices to demand conditions in every market. Appendix D provides further detail on how to compute prices under each alternative strategy.

We rely on a number of common simplifying assumptions (see, e.g., Nevo, 2000) in the counterfactual analyses. First, we assume that the values of the unobserved product characteristic $\Delta \xi_{j l t}$ are invariant to changes in price and demand, at least in the short run. This is reasonable as the suggested price changes only take place in Pennsylvania, while global demand for spirits likely determines the development of new spirit product offerings 
or modifications of existing products. Second, we continue to hold the utility of the outside good constant and normalized to zero. Lastly, we assume that wholesale prices remain fixed under the alternative pricing strategies. This simplification focuses our analysis on the interaction of changes in retail prices on consumption independent of changes in wholesale prices. $^{24}$

Since the $P L C B$, as a public agency, turns over both profit (in the form of markups on wholesale prices) and tax revenue (from collecting the $\$ 1.20$ handling fee and the $18 \%$ liquor tax) to the state treasury, we do not distinguish between these two sources of proceeds in our counterfactuals. Instead, we find shelf prices that maximize the $P L C B$ 's profit inclusive of tax revenue under alternative pricing rules. When backing out markups to compare the resulting optimal prices to prices under the current markup rule, we maintain the current liquor tax rate and pricing formula (see section 2.1).

One advantage of a discrete choice model of demand is that we can easily evaluate the mean impact of the counterfactual pricing policies in any given market. We report predicted quantity sold, markups, and variable profit under alternative pricing policies given the estimated demand system. An efficiency comparison requires a measure of consumer welfare in addition to producer surplus. According to Small and Rosen (1981), assuming away income effects and normalizing the constant of integration to zero, the mean expected consumer surplus in monetary terms under price vector $\hat{p}_{. l t}$ in market $l$ and at time $t$ is given by

$$
C S_{l t}\left(\hat{p}_{. l t}\right)=-\int \frac{1}{\alpha_{i}} \ln \left[\sum_{j=0, \ldots J_{l t}} \exp \left[V_{i j l t}\left(\hat{p}_{. l t}\right)\right]\right] d P_{D}\left(D_{i}\right) d P_{\nu}\left(\nu_{i}\right),
$$

where $V_{i j l t}$ is agent $i$ 's deterministic contribution to indirect utility from consuming product $j$ in market $l$, or $V_{i j l t}=u_{i j l t}-\epsilon_{i j l t}$ in Equation (1). The mean consumer surplus in a particular market $l$ results from integrating over the distributions of observable demographics for that local market, $P_{D}\left(D_{i}\right)$, and the estimated distribution of unobservable individual taste heterogeneity $P_{\nu}\left(\nu_{i}\right)$.

${ }^{24}$ It could be argued that distillers will change their prices to better accommodate the new pricing strategies of the $P L C B$. In Appendix $\mathbb{C}$ we repeat the counterfactual analysis allowing for endogenous wholesale prices. The idea is first to recover the distillers' marginal costs under the current pricing, fix these estimates and then compute the optimal vector of wholesale prices for each pricing strategy of the $P L C B$. Results are similar to those reported here, indicating that they are robust to the minor wholesale price adjustments induced by the different $P L C B$ 's pricing strategies. 
We also report the compensating variation from moving away from uniform pricing, or the average amount of income necessary to keep individuals in a given market indifferent between the counterfactual set of prices and the current ones of $p_{. t}^{30 \%}$, or

$$
C V_{l}(p)=\int \frac{1}{\alpha_{i}} \ln \left[\frac{\sum_{j=0, \ldots J_{l}} \exp \left[V_{i j l t}\left(\hat{p}_{. l t}\right)\right]}{\sum_{j=0, \ldots J_{l}} \exp \left[V_{i j l t}\left(p_{. t}^{30 \%}\right)\right]}\right] d P_{D}^{*}\left(D_{i}\right) d P_{\nu}^{*}\left(\nu_{i}\right)
$$

\subsection{Efficiency and Profit Implications of Alternative Pricing Strategies}

The following tables present the results of the four counterfactual pricing strategies compared to the benchmark $30 \%$ uniform markup currently employed by the PLCB. Table 10 summarizes what are arguably the most important results of this paper from a theoretical perspective. The first row shows the size of profits, total sales, the average price of a $750 \mathrm{ml}$ spirit bottle, consumer surplus, and overall welfare (ignoring externalities) as predicted by our full model demand estimates of Table 8. The rest of the table evaluates these same magnitudes for the alternative pricing strategies.

Table 10: Counterfactuals Summary Statistics

\begin{tabular}{lrrrrr}
\hline \hline \multirow{2}{*}{ Scenario } & \multicolumn{3}{c}{ Consumer } & & \multicolumn{2}{c}{ Average } \\
& Profits & Surplus & Welfare & Quantity & Price \\
\hline 30\% UNIFORM MARKUP & 53.79 & 57.89 & 111.68 & 8.56 & 15.39 \\
UNIFORM П-MAXIMIZING MARKUP (31.9\%) & 54.38 & 56.16 & 110.53 & 8.41 & 15.53 \\
PRODUCT-SPECIFIC & 59.88 & 50.41 & 110.29 & 7.81 & 18.86 \\
3RD DEGREE PRICE DISCRIMINATION & 62.13 & 49.12 & 111.25 & 8.09 & 18.90 \\
PERFECT COMPETITION & 41.97 & 94.45 & 136.42 & 12.77 & 13.67 \\
\hline
\end{tabular}

Profits, consumer surplus, and welfare are denominated in millions of dollars. Profits include liquor taxes. Quantity is millions of $750 \mathrm{ml}$ bottles. Average price is sales-weighted.

Restricting competition in the Pennsylvania liquor market has important consequences. Relative to setting price equal to the wholesale price plus taxes and fees, akin to perfect competition, the $P L C B$ charges an additional $\$ 1.72$ (about $13 \%$ ) for a $750 \mathrm{ml}$ spirit bottle on average, which reduces total sales by 4.21 million bottles, or $33 \%$, and consumer surplus by $\$ 36.56 \mathrm{~m}$, or $39 \%$.

One possible motivation for such high prices would be an attempt on the part of the $P L C B$ to use price to internalize some of the social costs of the externalities associated 
with alcohol consumption: the $P L C B$ may care for other health and road safety benefits to reduced consumption that private profit maximizing stores would ignore. Comparing the first and second lines of Table 10 shows, however, that the current $30 \%$ markup rule is very close to the $31.9 \%$ profit-maximizing uniform markup a multi-product monopolist would choose and indeed, the $P L C B$ is currently capturing nearly all of the potential monopoly profits when constrained to charging a single, uniform markup percentage across spirits sold. That is, even if controlling alcohol-related externalities were an objective, the $P L C B$ does not raise prices above and beyond the levels that a private firm would choose.

It could be the case, however, that the $P L C B$ does indeed value limiting alcoholrelated externalities but has complemented its simple pricing strategy with a similarly simple belief about consumer demand. We test this hypothesis by solving for the profit-maximizing markup conditional on the belief that demand is not systematically correlated with consumer demographics and is described by the IV specification in Table 8. Our findings support this hypothesis as the current $30 \%$ markup is significantly higher than the $21.5 \%$ markup that would maximize profit under the IV demand specification.

Next, we study the case where the monopolist engages in simple non-uniform markup pricing. "Product-Specific" pricing would allow the $P L C B$ to charge a different markup for each spirit in each time period although this markup is the same in every store in Pennsylvania. Thus, consumers will have no incentive to comparison shop to find better prices for the product of their preference; there is no possibility of arbitrage. Relative to the current markup policy, the $P L C B$ could increase profits by a substantial $11.3 \%$. This increase in profits is achieved by an increase of $\$ 3.47$, or $22.6 \%$, in the average unit price of a $750 \mathrm{ml}$ spirit bottle, resulting in only a moderate reduction of demand by 750 thousand bottles, or about $9 \%$. Consumer surplus falls by $\$ 7.48 \mathrm{~m}$, or $12.9 \%$. However, while consumers now only achieve $53.4 \%$ of their potential rents in the first-best competitive solution, this limited price discrimination strategy induces little additional efficiency losses $(\$ 1.39 \mathrm{~m}$ or $1.2 \%)$ relative to current prices, thus resulting mostly in an important redistribution of rents from consumers to the $P L C B$.

How much price discrimination is too much? In the context of the digital music industry, Shiller and Waldfogel (2011) estimate the potential revenue increases of moving to an individualized pricing system to be always larger than any non-discriminatory pricing strategy. While this is true from a theoretical perspective, it is questionable that such complex strategies yield large profit increases once we account for tariff design costs. By 
engaging in "Product-Specific" markup pricing, the $P L C B$ has to determine 233 optimal markups each period. Under "3rd Degree Price Discrimination", however, the $P L C B$ would aim at a much thinner segmentation of consumers, now screening them with respect to their preferences among 233 spirits within each of the 484 local markets in each period. This requires solving for 1,104,204 total markups in 2005. Our results show this is likely not a very profitable strategy: profits increase only by an additional $\$ 2.25 \mathrm{~m}$, or $3.76 \%$, relative to the much simpler "Product-Specific" markup strategy. The cost of computing this large number of optimal markups plus the costs of avoiding consumer arbitrage (perhaps by limiting sales to local residents in each store) will most likely exceed the limited incremental profits that this complex price discrimination strategy delivers. ${ }^{25}$

5.2.1 Markups. We can offer a more detailed description of the effect of the different pricing strategies in order to better understand the underlying mechanism behind the effects of these policies. Since "3rd Degree Price Discrimination" will be rarely implemented and its consequences are very similar to those of "Product-Specific" markup pricing, we focus on the latter and the "Uniform П-maximizing" strategy, analyzing the consequences of moving away from the current $P L C B$ pricing practices to easily implementable alternatives that better capture rents from consumer heterogeneous preferences.

Table 11: Product Percentage Markups by Spirit Type

\begin{tabular}{lccccc}
\hline \hline \multirow{2}{*}{ Spirit Type } & \multicolumn{2}{c}{ Uniform $(\Pi-m a x)$} & & \multicolumn{2}{c}{ Product-Specific } \\
\cline { 2 - 3 } & Average & SD & & Average & SD \\
\hline GIN & 31.9 & 0.0 & & 50.6 & 41.2 \\
RUM & 31.9 & 0.0 & & 59.6 & 23.5 \\
TEQUILA & 31.9 & 0.0 & & 21.8 & 15.1 \\
VODKA & 31.9 & 0.0 & & 40.7 & 27.2 \\
WHISKEY & 31.9 & 0.0 & & 39.9 & 31.3 \\
\hline CHEAP & 31.9 & 0.0 & & 67.4 & 31.7 \\
EXPENSIVE & 31.9 & 0.0 & & 26.3 & 13.3 \\
ALL PRODUCTS & 31.9 & 0.0 & & 42.7 & 30.2 \\
\hline
\end{tabular}

Unweighted average and standard deviation of the distribution of markups. Markups do not include the $18 \%$ liquor tax and a $\$ 1.20$ bottling fee.

Table 11 shows that "Product-Specific" price discrimination results in general markup increases, with the exception of tequila products. On average, exploiting consumer prefer-

25 Another alternative to reduce arbitrage costs might be pricing within larger geographic areas than the ones we consider here, such as the zone pricing strategies that are the topic of Chintagunta and Singh (2003). 
ences for specific spirits would allow the $P L C B$ to increase its markup to an average of $42.7 \%$, accounting for the estimated substitution elasticities across spirits. Average increases are larger for the lower-priced gin and rum products than for vodka and whiskey products. This is consistent with the sizable groups of relatively inelastic consumers of the former two product categories apparent in Figure2, relative to the more dispersed elasticity distributions for vodka and whiskey products.

Furthermore, markups are significantly larger, at $67.4 \%$, for less expensive, lower quality, spirits than for higher quality, expensive spirits, where markups actually fall to $26.3 \%$, on average. As before, we define CHEAP (EXPENSIVE) products as those spirits with benchmark prices less (greater) than the simple median price in their spirit type. Such a marked difference is consistent with the existence of well-defined product segments within each spirit type, as documented in Figure 2 in particular for gins and vodkas. A uniform percent markup common to all spirits cannot exploit this heterogeneity in demand responsiveness fully, trading off gains in profitability from raising across-the-board markups on relatively inelastically demanded products with the associated losses on relatively elastically demanded products.

Table 12: Changes in Product Price by Spirit Type with Product-Specific Pricing

\begin{tabular}{lccccc}
\hline \hline & \multicolumn{2}{c}{ Weighted Average Price } & \multicolumn{2}{c}{ Distribution of Price Changes $(\%)$} \\
\cline { 2 - 6 } Spirit Type & Benchmark & $\begin{array}{c}\text { Product- } \\
\text { Specific }\end{array}$ & Avg $\% \Delta$ & SD & $\% \Delta>0$ \\
\hline GIN & 14.5 & 18.2 & 12.8 & 25.4 & 67.4 \\
RUM & 12.5 & 15.3 & 19.7 & 15.0 & 96.3 \\
TEQUILA & 21.0 & 24.7 & -6.1 & 11.0 & 39.5 \\
VODKA & 16.1 & 18.7 & 6.8 & 17.4 & 66.4 \\
WHISKEY & 15.9 & 19.5 & 6.0 & 20.2 & 63.1 \\
\hline CHEAP & 11.4 & 14.6 & 24.3 & 19.3 & 96.5 \\
EXPENSIVE & 20.5 & 21.7 & -2.8 & 9.5 & 41.9 \\
ALL PRODUCTS & 15.4 & 18.9 & 8.0 & 19.5 & 68.9 \\
\hline
\end{tabular}

"Weighted Average Price" measures sales-weighted average prices by spirit type in dollars. Prices are calculated using the $P L C B$ formula and exclude temporary price discounts. "Avg $\% \Delta$ " is the unweighted average percentage change in prices relative to the benchmark. "SD" is the standard deviation in percentage price changes relative to the benchmark within the spirit type. "\% $\%>0 "$ is the percentage of price increases relative to the benchmark.

5.2.2 Prices. Table 12 breaks down the aggregate average prices reported in Table 10 by spirit type, reporting percentage price changes and percentages of products experiencing a 
Figure 3: Distribution of Percentage Price Changes by Spirit Type with Product-Specific Relative to Benchmark Prices
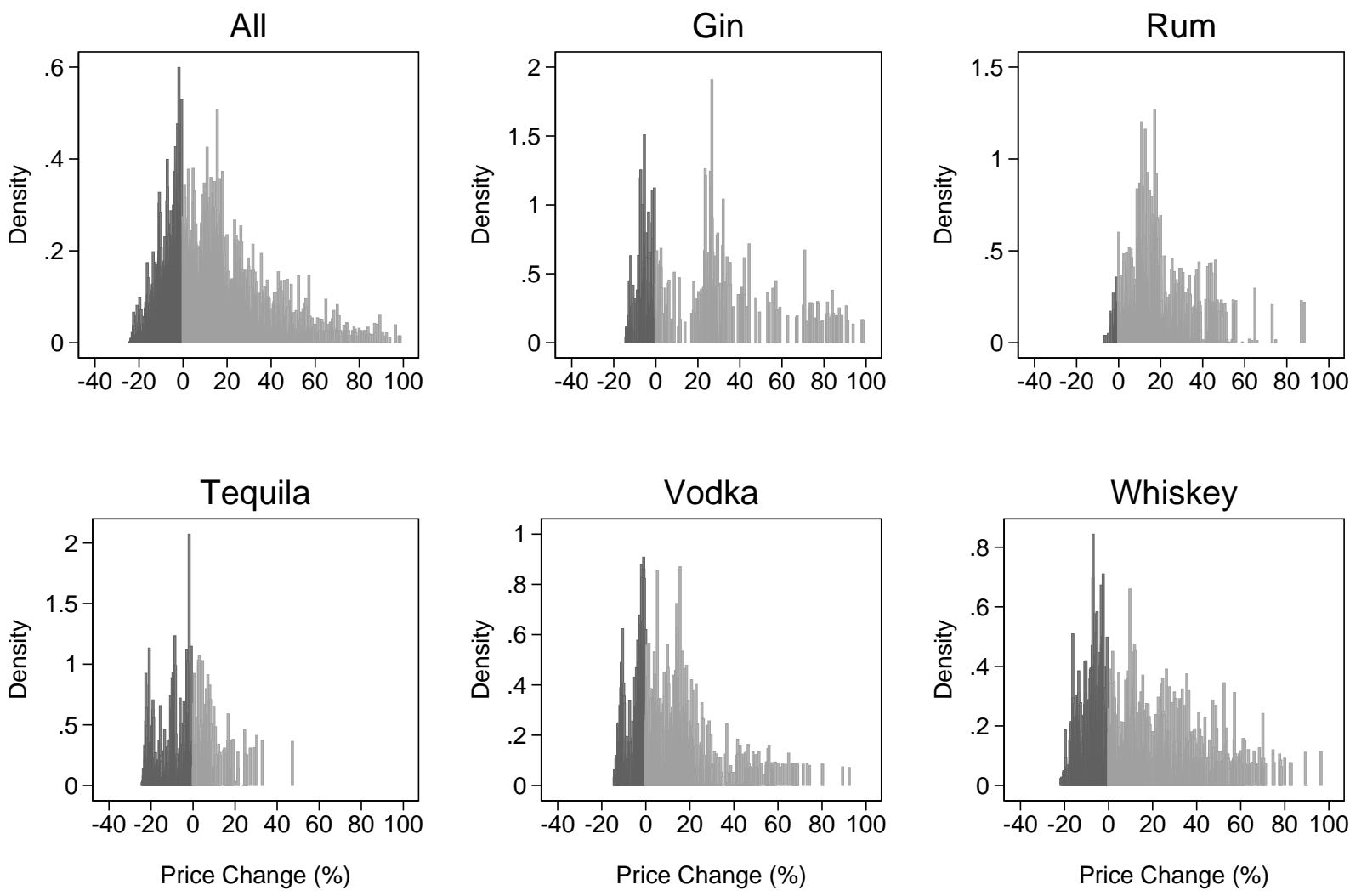

price increase under the alternative "Product-Specific" pricing strategy. "Product-Specific" markup pricing leads to larger price increases across all spirit types except tequila, and, mirroring the markup increases, has markedly different effects among low and high quality spirits. While increasing markups to an average of $67.4 \%$ leads to a $24.3 \%$ (sales-weighted) average price increase among inexpensive, low quality spirits, the $26.3 \%$ markup for expensive products reduces their average price by $2.8 \%$ relative to the current uniform pricing benchmark. Approximately $69 \%$ of all prices increase, and nearly all rums do. In contrast, the average tequila experiences a $6.1 \%$ price decrease, though the sales-weighted average price of tequila actually increases (from $\$ 21.0$ to $\$ 24.7$ ). This latter result is due to the fact that tequila products are relatively price-elastic (Table 9) so the reduction in price results in a sharp increase in demand, particularly for relatively expensive products. ${ }^{26}$ Figure 3 shows that most vodkas and whiskeys experience small price changes, with a sizable share of outliers. In the case of gins and rums, most products' price increases are substantial.

${ }^{26}$ Figure W.4 in the Web Appendix documents the change in price and corresponding shift in demand across products and spirit-type. 
5.2.3 Quantities Sold and Profits. Aggregate consumption drops by a modest $8.8 \%$ in response to a move to product-specific pricing. Table 13 describes how quantities sold and the resulting profits - change at the category level to generate this aggregate response. The price increases documented in Section 5.2 .2 above reduce consumption of vodka by $7.6 \%$, gin by $15.9 \%$, and rum by $31.2 \%$, while the $6.1 \%$ average price reduction of tequilas boosts their consumption by $46.1 \%$, thus increasing profits in this segment by $34.8 \%$ off a small base. Price increases reduce demand for cheap, low quality spirits by $35.3 \%$, thereby limiting profit increases to only $0.1 \%$ in this price segment. Demand for expensive, high quality spirits increase overall by an average of $25.5 \%$, boosting profits by $20.3 \%$ in this price segment. Combined, this results in the above overall profit increases of an estimated $11.3 \%$ from moving to simple "Product-Specific" price discrimination.

Table 13: Changes in Quantity and Profit by Spirit Type with Product-Specific Pricing

\begin{tabular}{lccccc}
\hline \hline & \multicolumn{2}{c}{ Quantity } & & \multicolumn{2}{c}{ Profits } \\
\cline { 2 - 3 } \cline { 6 - 6 } Spirit Type & Benchmark & $\% \Delta$ & & Benchmark & $\% \Delta$ \\
\hline GIN & 0.7 & -15.9 & & 4.4 & 9.6 \\
RUM & 1.8 & -31.2 & & 9.5 & 0.4 \\
TEQUILA & 0.4 & 46.1 & & 3.5 & 34.8 \\
VODKA & 2.9 & -7.6 & & 19.2 & 9.1 \\
WHISKEY & 2.6 & -1.5 & & 17.1 & 15.6 \\
\hline CHEAP & 4.8 & -35.3 & & 23.7 & 0.1 \\
EXPENSIVE & 3.7 & 25.5 & & 30.1 & 20.3 \\
ALL PRODUCTS & 8.6 & -8.8 & & 53.8 & 11.3 \\
\hline
\end{tabular}

Quantity sold is measured in millions of $750 \mathrm{ml}$ bottles while profits are in millions of dollars.

Section 2.2 documented heterogeneous preferences across demographic groups for different spirits. The varied demand responses to the counterfactual prices across spirit types suggest that a move toward "Product-Specific" markup pricing has a non-uniform effect on the purchase behavior and prices paid by different demographic groups. By enforcing uniform percent markups, the current system thus induces potentially important redistribution of rents between socio-economic groups, which we address in the following section.

\subsection{Taxation via Liquor Price Regulation}

Stigler (1971) first articulated regulatory capture, suggesting that regulation mostly served the interests of the firms in the regulated industry. Peltzman (1976) built on this view to 
consider consumers and other interest groups that may influence the design of regulatory rules and eventually the redistribution of rents among constituencies through the political process. $^{27}$ Although the regulation of the distribution and sale of alcohol is commonly motivated by public health and safety concerns, our previous analysis shows that the uniform percent markup rule de facto treats different individuals differently as the elasticity of demands for spirit products differ substantially across several identifiable groups. Thus, as first pointed out by Posner (1971), one-size-fits-all policies like the current pricing rule employed by the $P L C B$ lead to significant redistribution of rents among customers, despite not being a stated goal of the current regulation. ${ }^{28}$

Ross (1984) suggests a way of approaching the empirical evaluation of the magnitude of cross-subsidization by recovering the weight that each group of customers implicitly receives in the regulator's objective function. The idea, already explored by McFadden (1975), is to apply a revealed preference argument and find the weights that the government must place on different consumer groups' welfare to render its chosen action optimal. Ross (1984) shows, however, that in a setting with interdependent demands, such as ours, it is not possible to derive the implicit consumer weights uniquely when the number of products exceeds the number of consumer groups. We therefore take a more descriptive approach given the large number of spirits sold and the fact that consumer groups are not well identified entities, but instead characterized by the demographics of each local market. In Table 14 we correlate the product-level price, quantity, and profit changes induced by the "Product-Specific" pricing strategy in each market to product characteristics and demographics. In Table 15 we focus on the impact that our suggested pricing policies have on consumers' well-being by analyzing the market-level price, consumption, and surplus effects induced by this alternative pricing strategy.

5.3.1 Projecting Product-Level Effects in Each Market. Table 14 presents the results of regressing percentage changes in each product's price, quantity, and the induced profit changes in each local market and time period on product and market characteristics for the "Product-Specific" pricing counterfactual. An observation is the price change, quantity

27 These theories of regulation build upon the influential work by Olson (1965) on collective action and politics. Noll (1989) summarizes the political economy aspects of regulatory capture and Laffont and Tirole (1993, §11) elegantly formalize it within a principal-agent model of regulation.

28 See Laffont and Tirole $(1993, \S 11.7)$ for a formal analysis of a political economy model of cross-subsidization as the optimal response to the goals of interest groups representing the heterogeneous preferences of different consumers. 
Table 14: Projecting Product-level Results onto Product and Market Characteristics

\begin{tabular}{lllll}
\hline \hline & Elasticity & $\% \Delta$ Price & $\% \Delta$ Quantity & $\% \Delta$ Profits \\
\hline AGE $\geq 45$ YRS & -0.1574 & & -1.3266 & 1.2444 \\
EDUC $\geq$ COLLEGE & $(0.1229)$ & & $(4.5666)$ & $(1.6059)$ \\
HIGH INCOME & $-0.7371^{* * *}$ & & $24.1881^{* * *}$ & $3.2266^{*}$ \\
& $(0.1084)$ & & $(4.6535)$ & $(1.4010)$ \\
MINORITY & $-2.1174^{* * *}$ & & $23.4808^{* *}$ & $-11.3616^{* *}$ \\
& $(0.2119)$ & & $(8.7609)$ & $(3.6520)$ \\
GIN & -0.0059 & & 6.5547 & $5.8669^{* * *}$ \\
& $(0.1414)$ & & $(5.1043)$ & $(1.3778)$ \\
RUM & 0.2243 & 9.3010 & -15.3172 & -4.0521 \\
& $(0.4168)$ & $(9.4465)$ & $(13.5560)$ & $(3.6416)$ \\
TEQUILA & $0.6939^{* *}$ & 7.2815 & $-32.0465^{* * *}$ & $-11.2410^{* * *}$ \\
& $(0.2296)$ & $(5.0048)$ & $(7.3027)$ & $(2.2513)$ \\
VODKA & $-0.8817^{* *}$ & $-15.2469^{* * *}$ & 45.0305 & 11.3821 \\
& $(0.2812)$ & $(3.9584)$ & $(25.1593)$ & $(8.5591)$ \\
RUM $\times$ MINORITY & -0.2656 & -1.5586 & 6.9370 & -0.7893 \\
& $(0.2959)$ & $(5.4739)$ & $(10.0612)$ & $(1.8237)$ \\
VODKA $\times$ HIGH INCOME & $-0.4252^{*}$ & & $12.4363^{*}$ & $3.5342^{*}$ \\
& $(0.1685)$ & & $(5.3835)$ & $(1.5143)$ \\
HOLIDAY & 0.7029 & $-35.5235^{*}$ & -7.7599 \\
& $(0.3996)$ & & $(14.1004)$ & $(6.4430)$ \\
CONSTANT & -0.0061 & $14.6270^{* * *}$ & $-14.0603^{* * *}$ & $7.3883^{* * *}$ \\
& $(0.0302)$ & $(0.9161)$ & $(1.0159)$ & $(0.3239)$ \\
\hline$R^{2}$ & $-2.1336^{* * *}$ & $12.5915^{* * *}$ & $-14.2607^{*}$ & $10.9702^{* * *}$ \\
$\mathrm{~N}$ & $(0.2207)$ & $(3.7188)$ & $(7.1945)$ & $(1.7653)$ \\
\hline
\end{tabular}

The dependent variables are: the own-price elasticity of product $j$ in market $l$ at time $t$ under period $t$ 's benchmark prices; the percentage change in product $j$ 's price at $t$ in moving from benchmark to optimal product-specific prices; the percentage change in product $j$ 's quantity in $l$ at $t$ in moving from benchmark to optimal product-specific prices, and the corresponding percentage change in profit generated by $j$ in $l$ at $t$. All regressions weighted by sales under the current 30\% markup. Standard errors (clustered around product) are reported in parentheses with p-values denoted by ${ }^{*} p<0.10,{ }^{* *} p<0.05$, and ${ }^{* * *} p<0.01$. Market demographic attributes defined in footnote to Table 7

change, and the change in expected profit for each product-market-time period triplet. Since price changes for a given product in period $t$ are the same across markets (and therefore demographics), we project the set of product-period price changes $(4,503)$ on observable product characteristics and a holiday dummy.

For reference, we also include a regression model of the product's price elasticity at benchmark prices in each market and time period in the first column. This confirms some of the results already reported: products have more elastic demand in markets with a large 
share of high income and educated households than they do in markets with large shares of minorities. Across markets and products, the demand for tequila is significantly more elastic than that for other spirit types, particularly rum.

Prices decrease significantly for tequilas under "Product-Specific" pricing, but are substantially higher (about 15\%) for the average product during high-demand holiday periods. This latter point hints at the fact the $P L C B$ is currently departing substantially from profit maximization during those high-demand periods when the $30 \%$ markup rule does not allow it to exploit the seasonal demand peaks.

Relative to the levels under the $30 \%$ markup rule, demand responds to these price changes differently depending on the socioeconomic and demographic composition of consumers in each market. Thus, both highly educated consumers and minorities increase their overall alcohol consumption although the composition of their purchases might differ substantially. Consumption of tequila skyrockets following the general price reduction of this category while consumption of rum falls substantially. Consumption of an average spirit decreases further relative to the benchmark decrease over the holiday season due to the increase in price.

Changes to product-level profitability combine the above price and demand effects. Profitability gains for the average product are a sizable 10.97 percentage points higher during holiday periods. Profitability changes are also increasing in the share of minority population as a one standard deviation increase in the share of minority customers (18 percentage points), raises profitability by 1.06 percentage points on non-rum products. For rums, the effect is more pronounced since the group's taste preference for rums offsets increases in price. Even in minority-only markets, however, profitability on rums falls by $7.71 \%$, while it drops by $10.08 \%$ in the average market with a $12.3 \%$ minority population.

Household income has a similarly sizable effect on profitability changes: holding all other demographics at their mean values, increasing the share of high-income households in a market by one standard deviation, or 12.7 percentage points, above the mean of $39.2 \%$ results in a drop in the percentage profit gain from $4.9 \%$ for the average whiskey - the category with the largest number of products - to $3.49 \%$.

5.3.2 Projecting Market-Level Effects. The previous section suggested that positive profit gains from moving to "Product-Specific" prices were limited for products sold in high-income 


\section{Table 15: Projecting Market-Level Aggregate Effects from Moving to Product-Specific Prices onto Market Characteristics}

\begin{tabular}{llllll}
\hline \hline & $\% \Delta$ Profits & $\% \Delta$ Price & $\% \Delta$ Quantity & $C V(\$)$ & $\% C V<0$ \\
\hline AGE $\geq 45$ YRS & 4.9653 & -0.7626 & 23.3607 & $-6.3592^{*}$ & 28.9655 \\
& $(8.1856)$ & $(4.8851)$ & $(21.2751)$ & $(3.0882)$ & $(16.7734)$ \\
EDUC $\geq$ COLLEGE & $9.5391^{* * *}$ & $-4.3865^{* * *}$ & $25.8475^{* * *}$ & -2.3732 & $88.0873^{* * *}$ \\
& $(1.7707)$ & $(1.2754)$ & $(3.2372)$ & $(1.3541)$ & $(6.9017)$ \\
HIGH INCOME & 0.2749 & -1.8167 & $18.6927^{* * *}$ & -3.1322 & $48.7427^{* * *}$ \\
& $(2.3065)$ & $(1.8726)$ & $(4.7324)$ & $(1.6214)$ & $(8.5870)$ \\
MINORITY & $5.9066^{*}$ & $4.1157^{* *}$ & 3.3446 & $3.3537^{* *}$ & -3.4659 \\
& $(2.4575)$ & $(1.4452)$ & $(5.0639)$ & $(1.1628)$ & $(6.1486)$ \\
DEMOCRAT & 3.5887 & $3.3235^{*}$ & -5.2727 & $3.9542^{* * *}$ & $-10.4804^{*}$ \\
& $(2.0181)$ & $(1.5923)$ & $(3.9541)$ & $(1.1937)$ & $(5.2918)$ \\
CHURCHES PER CAPITA & -4.7582 & 5.9058 & -7.8052 & $-5.8138^{*}$ & 8.0067 \\
& $(3.1460)$ & $(3.8039)$ & $(6.7916)$ & $(2.8437)$ & $(13.4674)$ \\
POPULATION DENSITY & -0.0290 & $-0.1754^{* * *}$ & $0.2727^{* *}$ & -0.0618 & $0.7823^{* *}$ \\
& $(0.0507)$ & $(0.0344)$ & $(0.0846)$ & $(0.0351)$ & $(0.2649)$ \\
CONSTANT & 3.3511 & $21.4215^{* * *}$ & $-29.2903^{* * *}$ & $6.3508^{* * *}$ & $-21.1780^{*}$ \\
& $(3.4256)$ & $(2.2390)$ & $(8.6610)$ & $(1.6323)$ & $(8.3229)$ \\
\hline$R^{2}$ & 0.1783 & 0.1713 & 0.3626 & 0.2170 & 0.6741 \\
$\mathrm{~N}$ & 484 & 484 & 484 & 484 & 484 \\
\hline
\end{tabular}

An observation is a market. The dependent variables are: the percentage change in profit, weighted average prices, and quantity consumed of all products $J_{l t}$ in moving from benchmark to product-specific prices, averaged over time periods $t$, in specifications (1)-(3), respectively; and the average CV from the price change and the average share of market consumers with a negative CV in (4) and (5), respectively. Robust standard errors reported in parentheses with p-values denoted by ${ }^{*} p<0.10,{ }^{* *} p<0.05$, and ${ }^{* * *} p<$ 0.01. Market demographic attributes defined in the caption of Table 7 . DEMOCRAT is the share of the population registered as democrats as of 2009 according to the Pennsylvania Department of State, https:// Www.pavoterservices.state.pa.us. CHURCHES PER CAPITA denotes the number of establishments located in the market's census blocks with a primary NAICS code of 8131 (source: Reference USA) divided by the market population.

markets, but more pronounced when sold in minority markets. We now turn to the implications at the market level: how do these patterns translate into which markets - in terms of their demographic profile - contribute larger profit gains to the PLCB's bottom line? Similarly, while prices increase on average, there is significant variation in price changes. How does this variation translate into which consumer types are hurt and which benefit from the alternative prices?

In Table 15, we show results from correlating each market's percentage change in aggregate annual profit, sales-weighted average prices paid, and the share of consumers whose compensating variation is negative (i.e., who are better off), as well as the annualized compensating variation in dollars for a representative consumer, in moving to "ProductSpecific" pricing with observable market demographics. We include, beyond our standard 
demographics, the additional market characteristics of population density and the political and religious orientation of residents, as proxies for other profit-unrelated potential influences on the regulator's objective function. We also experimented with adding lagged counts of alcohol-related crimes from Pennsylvania's Uniform Crime Reporting System as a proxy for the potential negative externalities of alcohol consumption. Since these data are not available for all markets, but the remaining coefficients are robust to their inclusion, we suppress these results for the sake of brevity.

Table 15 presents compelling evidence that the current uniform 30\% markup rule across all products induces significant rent redistribution. If the $P L C B$ were to switch to a more flexible "Product-Specific" pricing strategy, it would increase prices to products that minorities favor and thus their average expenditure per bottle, but decrease prices for high income and college educated households. Both in statistical and economic significance, the effects are most pronounced for minorities and college educated households; prices paid increase by 0.74 and 0.61 percentage points, respectively, in moving from the average market to a market with one standard deviation higher share of minority households or lower share of college-educated households. These price changes leave demand by minorities almost unchanged, however, in line with the group's estimated demand responsiveness. Consumption responses are increasing in the share of high-income or highly educated consumers; a one-standard deviation increase in their shares is associated with an increase in the quantity response of 2.37 and 3.57 percentage points, respectively. On net, by switching to a more flexible pricing strategy, the $P L C B$ 's profits will increase in predominantly minority markets because of the group's limited demand response to price increases. Profits will also increase in markets with large college educated populations whose more price responsive demand leads to a substantial increases after prices of their favored spirits fall. Last, prices would be lower and demand higher in high population density, urban areas. Similarly prices would increase in markets with larger shares of registered democrats although in this case demand response does not change significantly.

Few demographics correlate significantly with the average compensating variation on observable market characteristics. Minorities and registered democrats - groups with substantial overlap in Pennsylvania - require compensation to make them indifferent between the current system and one where the $P L C B$ is allowed to use a more flexible pricing strategy, reflecting that under the current system, their favored products, notably rum, gin, and inexpensive spirits, are most underpriced. A one standard deviation increase in minority 
share or in the share of registered democrats (18\% and 15\%, respectively) increases average compensating variation by 60 and 59 cents, respectively.

This contrasts with the situation of high income and college educated markets. While the effect on mean compensating variation is negative but insignificant in both cases, we find that the proportion of consumers who benefit from adopting a more flexible pricing strategy (last column of Table 15) increases rapidly in affluent and educated markets: 0.49 and 0.88 percentage points, respectively, for every one percentage point increase in the share of high-income and college-educated consumers. These customers are worse off under the current system that works as a taxing mechanism to transfer rents from high income and educated consumers with elastic demands to minorities with less elastic demands for spirits.

Evidently, changing the current pricing rule would have non-uniform effects both across and within racial or socioeconomic groups. Table 15 only documents the correlation of these demographic attributes with the average compensating variation in each market, but does not speak to the distributional implications for the well-being of older, collegeeducated, high-income, and minority populations. In order to document these disparate effects, we classify markets according to age, education, income, and minority levels relative to the median across Pennsylvania. In Table 16 we report the descriptive statistics for the distribution of compensating variation in each of these market types. ${ }^{29}$

Table 16: Compensating Variation by Market's Demographic Type

\begin{tabular}{llccc}
\hline \hline Market Type & & Avg $(\$)$ & Median $(\$)$ & $\% C V<0$ \\
\hline \multirow{2}{*}{ AGE } & $<$ Median & 4.10 & 2.11 & 8.89 \\
& $\geq$ Median & 3.07 & 1.77 & 11.16 \\
\hline \multirow{2}{*}{ COLLEGE } & $<$ Median & 2.76 & 1.67 & 12.18 \\
& $\geq$ Median & 4.62 & 2.30 & 7.34 \\
\hline \multirow{2}{*}{ INCOME } & $<$ Median & 4.17 & 2.38 & 1.83 \\
& $\geq$ Median & 3.13 & 1.56 & 17.10 \\
\hline \multirow{2}{*}{ MINORITY } & $<$ Median & 2.82 & 1.58 & 12.52 \\
& $\geq$ Median & 4.45 & 2.44 & 7.28 \\
\hline All & & 3.62 & 1.94 & 9.95 \\
\hline
\end{tabular}

An observation is average compensating variation in a market. Markets are classified based on how their average demographic attributes compare to the median across markets. AGE refers to the population share in the market above the age of 45, COLLEGE to the market's share of the population with at least a four-year college education, INCOME to the market's average household income, and MINORITY to the share of non-whites.

29 The complete empirical distributions by market type are are displayed in Figure W.3 of the Web Appendix. 
Overall, only $10 \%$ of Pennsylvanians are better off under a more flexible pricing such as the "Product-Specific" markup strategy. In other words, 90\% of Pennsylvanians prefer the current $30 \%$ uniform markup and will remain indifferent towards phasing the current regulation out only if they get compensated an average of $\$ 3.62$ per customer. This amounts to approximately $12.8 \%$ of average annual expenditure on the $P L C B$ liquor products in our sample of $\$ 28.25$, a sizable effect.

Not controlling for other demographics, this effect is most pronounced in high income markets; the average compensating variation in markets with above-median incomes amounts to $\$ 3.13$, compared to $\$ 4.17$ in below-median income markets, suggesting that high-income consumers are hurt less than their low-income counterparts. Accordingly, we find that $17.10 \%$ of consumers in high-income markets are better off under "Product-Specific" markup pricing compared to only $1.8 \%$ of consumers in low-income markets. The variation in CV is similarly high when classifying markets based on the size of their minority population. In markets with below-median shares of minority consumers, the CV is only $\$ 2.82$, compared to $\$ 4.45$ in markets with large minority populations, suggesting that the average minority consumer requires above average compensation to be indifferent between the two pricing strategies.

Although purely descriptive, in sum our results indicate that while the majority of households benefit from the current uniform prices, minorities in democratic-leaning districts are the disproportionate beneficiaries of the current pricing regulation at the expense of high income and educated households, suggesting a possible role for political economy considerations in $P L C B$ decision making.

\section{Concluding Remarks}

Limited systematic evidence exists to evaluate the performance of a public enterprise such as the $P L C B$. The current paper focuses its analysis on a behavioral aspect that is commonly overlooked: the implicit rent redistribution associated with price distortions induced by an one-size-fits-all policy in the presence of heterogeneous consumers. As such, we study the intensive margin of regulated alcohol distribution - pricing - and complement related work by Seim and Waldfogel (2013) who analyze the size of the PLCB's store network, or the extensive margin, as policy tools to affecting alcohol consumption in Pennsylvania. 
We use a rich data set on consumer demand under the current uniform percent markup policy to study the welfare implications of its pricing policy. Our approach requires the estimation of a parsimonious discrete choice demand model where demand for liquors depends on both observable and unobservable product characteristics and where we can account for many of the important dimensions along which customers differ: income, educational attainment, and minority status. This model is then used to evaluate the effects of alternative pricing strategies that the $P L C B$, following common business practices in private retailing, could adopt. The model delivers theoretical and empirical results.

First, we show that the current $P L C B$ markup is nearly indistinguishable from the markup a profit-maximizing, multi-product monopolist would choose. We argue this is due to the fact that the $P L C B$ likely fails to account for heterogeneity in consumer preferences and, therefore, incorrectly concludes that the current uniform markup sets prices sufficiently high to both reduce alcohol consumption and generate revenue for the state.

Second, our evidence indicates that the use of a third degree price discrimination mechanism does not likely compensate the cost of implementing such a complex strategy. This piece of evidence, together with others mentioned in the body of the paper, should influence future theoretical modeling of nonlinear pricing models. There is a current disconnect between the abstract models written by theorists, focused on achieving efficiency given the sources of consumer heterogeneity, and the business practice that makes use of simple price discrimination mechanisms. This paper presents, to our knowledge, the first empirical evaluation of the relative performance of several such mechanisms in the case of third-degree price discrimination.

Third, an important empirical finding that drives much of our counterfactual results is that the demand for spirits is more elastic for expensive products favored by high income and educated households than the demand for inexpensive spirits products favored by minorities. Analyzing substitution patterns we conclude that buyers of expensive spirits can more easily substitute to similar products or move down to lower quality alternatives. Fewer options, however, are available for minorities so an increase in the price of their favored product leads them to leave the market altogether and purchase more distant substitutes such as beer, inexpensive wines, or sodas. We further document that within liquor categories, spirits appear to be vertically differentiated. 
Finally, our model delivers the first empirical evaluation of Posner's regulation-induced rent redistribution argument. Our results indicate that the current system acts as a tax mechanism by redistributing rents from higher income and educated consumers towards lower income and minority consumers. This rent redistribution is certainly an aspect that is rarely discussed when evaluating the performance of public monopolies like the $P L C B$. Interestingly, the cost of the current system falls on a small share of the population and thus the overwhelming majority of Pennsylvanians would suffer under a less restricted pricing practice, whether this is carried out by a reformed $P L C B$ or by private companies. In the latter case, entry of new competitors and opening of new stores may alter the welfare effects that we study here and may extend beyond the pricing effects we consider.

\section{References}

ACCRA (2008) Cost of Living Index, Arlington, VA: The Council for Community and Economic Research.

Adda, J. and R. W. Cooper (2003) Dynamic Economics: Quantitative Methods and Applications, Vol. 1 of MIT Press Books: The MIT Press.

Aguirre, I. n., S. Cowan, and J. Vickers (2010) "Monopoly Price Discrimination and Demand Curvature," American Economic Review, Vol. 100, pp. 1601-1615.

Armstrong, M. (1999) "Price Discrimination by a Many-Product Firm," Review of Economic Studies, Vol. 66, pp. 151-168.

Armstrong, M. and J. S. Vickers (2001) "Competitive Price Discrimination," RAND Journal of Economics, Vol. 32, pp. 579-605.

Ashenfelter, O. and D. Hosken (2010) "The Effect of Mergers on Consumer Prices: Evidence from Five Mergers on the Enforcement Margin," Journal of Law and Economics, Vol. 53, pp. pp. 417-466.

Berry, S. (1994) "Estimating Discrete-Choice Models of Product Differentiation," RAND Journal of Economics, Vol. 25, pp. 242-262.

Berry, S., J. Levinsohn, and A. Pakes (1995) "Automobile Prices in Market Equilibrium," Econometrica, Vol. 63, pp. 841-890.

Borenstein, S. (2012) "The Redistributional Impact of Nonlinear Electricity Pricing," American Economic Journal: Economic Policy, Vol. 4, pp. 56-90. 
Borenstein, S. and L. W. Davis (2012) "The Equity and Efficiency of Two-Part Tariffs in U.S. Natural Gas Markets," Journal of Law and Economics, Vol. 55, pp. 75-128.

Borenstein, S. and S. Holland (2005) "On the Efficiency of Competitive Electricity Markets with Time-Invariant Retail Prices," RAND Journal of Economics, Vol. 36, pp. 469493.

Carpenter, C. and C. Dobkin (2010) "Alcohol regulation and crime," in Controlling crime: Strategies and tradeoffs: University of Chicago Press, pp. 291-329.

Chintagunta, J.-P., Pradeep Dubé and V. Singh (2003) "Balancing Profitability and Customer Welfare in a Supermarket Chain," Quantitative Marketing \& Economics, Vol. 1, pp. 111-147.

Chu, C. S., P. Leslie, and A. Sorensen (2011) "Bundle-Size Pricing as an Approximation to Mixed Bundling," American Economic Review, Vol. 101, pp. 263-303.

Corts, K. S. (1995) "Regulation of a Multi-Product Monopolist: Effects on Pricing and Bundling," Journal of Industrial Economics, Vol. 43, pp. 377-397.

Dubé, J.-P., J. T. Fox, and C.-L. Su (2012) "Improving the Numerical Performance of Static and dynamic Aggregate Discrete Choice Random Coefficients Demand Estimation," Econometrica, Vol. 80, pp. 2231-2267.

Feldstein, M. S. (1971) "Equity and Efficiency in Public Sector Pricing: The Optimal TwoPart Tariff," Quarterly Journal of Economics, Vol. 86, pp. 175-187.

Gyimah-Brempong, K. (2001) "Alcohol Availability and Crime: Evidence from Census Tract Data," Southern Economic Journal, Vol. 68, No. 1, pp. 2-21, 07.

Heaton, P. (2012) "Sunday Liquor Laws and Crime," Journal of Public Economics, Vol. 96, No. 1-2, pp. 42-52, 02.

Hendel, I. (1999) "Estimating Mulitple-Discrete Choice Models: An Application to Computerization Returns," Review of Economic Studies, Vol. 66, pp. 423-446.

Hendel, I. and A. Nevo (2006) "Measuring the Implications of Sales and consumer Inventory Behavior," Econometrica, Vol. 74, pp. 1637-1673.

Katz, M. L. (1983) "Non-Uniform Pricing, Output and Welfare under Monopoly," The Review of Economic Studies, Vol. 50, pp. 37-56.

Laffont, J.-J. and J. Tirole (1993) A Theory of Incentives in Procurement and Regulation, Cambridge, MA: MIT Press.

Leung, S. F. and C. E. Phelps (1993) "My Kingdom for a Drink?: A Review of the Price Sensitivity of Demand for Alcoholic Beverages," in M. Hilton and G. Bloss eds. Economics and the Prevention of Alcohol-Related Problems, Washington, DC: National Institute on Alcohol Abuse and Alcoholism, NIH Publication No. 93-3513. 
Markowitz, S. (2005) "Alcohol, Drugs and Violent Crime," International Review of Law and Economics, Vol. 25, No. 1, pp. 20-44.

Mauleg, D. A. (1983) "Bounding the Welfare Effects of Third-Degree Price Discrimination," American Economic Review, Vol. 93, pp. 1011-1021.

Mauleg, D. A. and C. M. Snyder (2006) "Bounding the Relative Profitability of Price Discrimination," Industrial Journal of Industrial Organization, Vol. 24, pp. 995-1011.

McDonald, J. B. (1984) "Some Generalized functions for the Size Distribution of Income," Econometrica, Vol. 52, pp. 647-663.

McFadden, D. L. (1975) "The Revealed Preferences of a Government Bureaucracy: Theory," BELL Journal of Economics, Vol. 6, pp. 401-416.

Mikians, J., L. Gyarmati, V. Erramilli, and N. Laoutaris (2012) "Detecting price and search discrimination on the Internet," in Proceedings of the 11th ACM Workshop on Hot Topics in Networks, pp. 79-84, Association for Computing Machinery.

National Alcohol Beverage Control Association (2005) NABCA Survey Book, Alexandria, VA.

Nevo, A. (2000) "Mergers with differentiated Products: The Case of the Ready-to-Eat Cereal Industry," RAND Journal of Economics, Vol. 31, pp. 395-421.

(2001) "Measuring Market Power in the Ready-to-Eat Cereal Industry," Econometrica, Vol. 69, pp. 307-342.

Noll, R. G. (1989) "Economic Perspectives on the Politics of Regulation," in R. Schmalensee and R. Willig eds. Handbook of Industrial Organization, Vol. 2, New York, NY: NorthHolland.

Olson, M. (1965) The Logic of Collective Action, Cambridge, MA: Harvard University Press.

Orbach, B. Y. and L. Einav (2007) "Uniform Prices for Differentiated Goods: The Case of the Movie-Theater Industry," International Review of Law and Economics, Vol. 27, pp. 129-153.

Peltzman, S. (1976) "Toward a More General Theory of Regulation," Journal of Law and Economics, Vol. 19, pp. 211-240.

Posner, R. A. (1971) "Taxation by Regulation," BELL Journal of Economics and Management Science, Vol. 2, pp. 22-50.

Puller, S. L. and L. Taylor (2012) "Price discrimination by Day-of-Week Purchase: Evidence from the U.S. Airline Industry," Journal of Economic Behavior and Organization, Vol. 84, pp. 801-812.

Robinson, J. (1933) Economics of Imperfect Competition, London, UK: Macmillan. 
Rochet, J.-C. and P. Choné (1998) "Ironing, Sweeping, and Multidimensional Screening," Econometrica, Vol. 66, pp. 783-826.

Rochet, J.-C. and L. A. Stole (2002) "Nonlinear Pricing with Random Participation," The Review of Economic Studies, Vol. 69, pp. 277-311.

Rogerson, W. P. (2003) "Simple Menus of Contracts in Cost-Based Procurement and Regulation," American Economic Review, Vol. 93, pp. 919-926.

Ross, T. W. (1984) "Uncovering Regulators' Social Welfare Weights," RAND Journal of Economics, Vol. 15, pp. 152-155.

Schmalensee, R. (1981) "Output and Welfare Implications of Monopolistic Third-Degree Price Discrimination," American Economic Review, Vol. 71, pp. 242-247.

Schwartz, M. (1990) "Third-Degree Price Discrimination and Output: Generalizing a Welfare Result," American Economic Review, Vol. 80, pp. 1259-1262.

Seim, K. and J. Waldfogel (2013) "Public Monopoly and Economic Efficiency: Evidence from the Pennsylvania Liquor Control Boards Entry Decisions," American Economic Review, Vol. 103, pp. 831-862.

Shiller, B. and J. Waldfogel (2011) "Music for a Song: An Empirical Look at Uniform Pricing and its Alternatives," Journal of Industrial Economics, Vol. 59, pp. 630-660.

Small, K. A. and H. S. Rosen (1981) "Applied Welfare Economics with Discrete Choice Models," Econometrica, Vol. 49, pp. 105-130.

Stigler, G. J. (1971) "The Theory of Economic Regulation," BELL Journal of Economics and Management Science, Vol. 2, pp. 3-21.

Teh, B.-R. (2008) "Do Liquor Stores Increase Crime and Urban Decay? Evidence from Los Angeles." Working paper, University of Berkeley.

U.S. Department of Health and Human Services (2010) Results from the 2010 National Survey on Drug Use and Health: Summary of National Findings, http://www.samhsa. gov/data/NSDUH/2k10ResultsRev/NSDUHresultsRev2010.htm.

Varian, H. R. (1985) "Price Discrimination and Social Welfare," American Economic Review, Vol. 75 , pp. $870-875$.

Villas-Boas, S. B. (2007) "Vertical Relationships between Manufacturers and Retailers: Inference with Limited Data," Review of Economic Studies, Vol. 74, No. 2, pp. 625-652.

Wilson, R. B. (1993) Nonlinear Pricing, New York, NY: Oxford University Press. 


\section{Appendix}

\section{A Estimation Algorithm}

In this Appendix, we provide a step-by-step summary of the estimation algorithm we employ, which is similar in methodology to $B L P$, Nevo (2000) and Nevo (2001). It proceeds in two stages. In the first stage, we characterize each product's mean utility $\delta_{j l t}$ as a function of price, an indicator for whether the time period $t$ overlaps with the end-of-year holiday period, and product fixed effects. For a given guess at the first-stage parameters $\theta$, we then calculate the value of the objective function using the following procedure:

1. For each market $l$ and time period $t$, use $\theta$ and the observed market shares to compute $\delta_{j l t}$ using the contraction mapping outlined in Appendix I of $B L P$. In order to ensure convergence to consistent stable estimates we follow the advice of Dubé, Fox and Su $(2012, \S 4.2)$ and set the norm for mean value contraction equal to 1e-14.

2. Construct a vector of mean utilities across markets and time periods, $\delta=\left[\delta_{111}, \ldots, \delta_{j l t}\right]$.

3. Regress $\delta$ on prices, the holiday indicator, and product fixed effects to recover the mean price and holiday coefficients $\alpha$ and $\gamma$ and the joint contribution of $x_{j} \beta$ and $\xi_{j}$ to mean utility.

4. Recover the unobserved product characteristic $\Delta \xi_{j t}$ defined in Equation (8), exploiting the assumption of the mean zero, i.i.d. distribution of $\zeta_{j l t}$.

5. Compute the value of the objective function:

$$
\|G(\theta)\|=\Delta \xi^{\prime} Z W Z^{\prime} \Delta \xi .
$$

We update $\theta$ and return to step (1) unless $\|G\|$ is sufficiently small. In robustness checks summarized in Table B.1, we include as additional determinants of mean utility an indicator for state border locations and an indicator for whether the store serving market $l$ is a premium store.

In the second stage, we project the estimated product fixed effects on the set of product characteristics $x_{j}$ (i.e., proof, product quality, dummies indicating whether the product is flavored or imported, and spirit type) by means of a minimum distance estimator. Second stage standard errors were computed following Nevo (2001).

As commonly noted, finding a global solution to a nonlinear problem such as this is difficult and any line, gradient, or simplex search will likely only result in a local solution. 
Instead, we employ a simulated annealing algorithm, which is designed to increase the probability of finding the global minimum. We further looped the estimation over different initial guesses. First stage standard errors were computed following Adda and Cooper (2003).

\section{B Robustness of Results}

Table B.1: Alternative IV Results from Logit Demand

\begin{tabular}{|c|c|c|c|c|c|}
\hline & \multirow{2}{*}{$\begin{array}{c}\text { OLS } \\
\text { (i) }\end{array}$} & \multicolumn{4}{|c|}{ IV } \\
\hline & & (ii) & (iii) & (iv) & (v) \\
\hline PRICE & $\begin{array}{l}-0.1576^{* * *} \\
(0.0094)\end{array}$ & $\begin{array}{l}-0.2056^{* * *} \\
(0.0183)\end{array}$ & $\begin{array}{l}-0.2008^{* * *} \\
(0.0181)\end{array}$ & $\begin{array}{l}-0.2088^{* * *} \\
(0.0184)\end{array}$ & $\begin{array}{l}-0.1906^{* * *} \\
(0.0173)\end{array}$ \\
\hline Product Fixed Effects & $\mathrm{Y}$ & $\mathrm{Y}$ & Y & $\mathrm{Y}$ & Y \\
\hline Premium Stores & $\mathrm{Y}$ & Y & $\mathrm{N}$ & $\mathrm{Y}$ & $\mathrm{Y}$ \\
\hline Border Stores & Y & $\mathrm{Y}$ & $\mathrm{Y}$ & $\mathrm{N}$ & $\mathrm{Y}$ \\
\hline Holiday Period & Y & Y & Y & $\mathrm{Y}$ & $\mathrm{N}$ \\
\hline$\overline{R^{2}}$ & 0.982 & 0.982 & 0.984 & 0.982 & 0.983 \\
\hline Observations & $1,104,204$ & $1,104,204$ & 895,443 & 932,542 & 923,590 \\
\hline \multicolumn{6}{|l|}{ Elasticity Statistics: } \\
\hline Average & -2.54 & -3.31 & -3.19 & -3.36 & -3.06 \\
\hline Sales-weighted & -2.38 & -3.10 & -2.96 & -3.14 & -2.86 \\
\hline Median & -2.20 & -2.88 & -2.81 & -2.92 & -2.67 \\
\hline Standard Deviation & 1.11 & 1.45 & 1.38 & 1.47 & 1.34 \\
\hline Percentage Inelastic & 1.94 & 0.00 & 0.08 & 0.00 & 0.12 \\
\hline Off-Premise Spirit Demand & -2.05 & -2.67 & -2.61 & -2.70 & -2.51 \\
\hline \multicolumn{6}{|l|}{ First Stage: } \\
\hline$F-$ Statistic & & 20.418 & 19.566 & 25.363 & 19.020 \\
\hline Percentage Significant & & 100.0 & 100.0 & 100.0 & 100.0 \\
\hline
\end{tabular}

Dependent variable $\log \left(S_{j m t}\right)-\log \left(S_{0 m t}\right)$. Robust standard errors in parentheses with p-values denoted by ${ }^{*} p<0.10$, ${ }^{* *} p<0.05$, and ${ }^{* * *} p<0.01$. "Percentage Significant" is the percentage of instruments that are significant in the first-stage at the $5 \%$ level. Instruments based on prices from other states as described in the text. "Off-Premise Spirit Demand" is the price elasticity of total PLCB spirit sales $(750 \mathrm{ml}$ bottles). 
Table B.2: Alternative Full Model Demand Estimates

\begin{tabular}{|c|c|c|c|c|}
\hline & $\begin{array}{c}\text { Main } \\
\text { Specification }\end{array}$ & $\begin{array}{l}\text { No Premium } \\
\text { Stores }\end{array}$ & $\begin{array}{l}\text { No Border } \\
\text { Stores }\end{array}$ & No Holidays \\
\hline \multicolumn{5}{|l|}{ Mean Utility $(\alpha, \beta)$} \\
\hline PRICE & $\begin{array}{l}-0.1813^{* * *} \\
(0.0088)\end{array}$ & $\begin{array}{l}-0.1579 * * * \\
(0.0054)\end{array}$ & $\begin{array}{l}-0.1940^{* * *} \\
(0.0097)\end{array}$ & $\begin{array}{l}-0.1471^{* * *} \\
(0.008)\end{array}$ \\
\hline HOLIDAY & $\begin{array}{l}1.0944^{* * *} \\
(0.0884)\end{array}$ & $\begin{array}{l}0.9877^{* * * *} \\
(0.0411)\end{array}$ & $\begin{array}{l}1.5361^{* * *} \\
(0.0865)\end{array}$ & - \\
\hline \multicolumn{5}{|l|}{ Standard Dev. $(\sigma)$} \\
\hline PRICE & $\begin{array}{c}0.0015 \\
(0.1145)\end{array}$ & $\begin{array}{c}0.0007 \\
(0.1002)\end{array}$ & $\begin{array}{c}0.0015 \\
(0.0605)\end{array}$ & $\begin{array}{c}0.0094 \\
(0.0138)\end{array}$ \\
\hline CONSTANT & $\begin{array}{c}0.0138 \\
(0.1738)\end{array}$ & $\begin{array}{l}0.0073^{* *} \\
(0.0711)\end{array}$ & $\begin{array}{c}0.1677 \\
(0.1459)\end{array}$ & $\begin{array}{c}0.0651 \\
(0.0947)\end{array}$ \\
\hline \multicolumn{5}{|l|}{ Interactions $(\Pi)$} \\
\hline INCOME $\times$ CONSTANT & $\begin{array}{l}2.2958^{* * *} \\
(0.1166)\end{array}$ & $\begin{array}{l}2.6644^{* * * *} \\
(0.0718)\end{array}$ & $\begin{array}{l}1.6506^{* * *} \\
(0.2125)\end{array}$ & $\begin{array}{l}2.9963^{* * *} \\
(0.0468)\end{array}$ \\
\hline PRICE $\times$ INCOME & $\begin{array}{l}-0.0487^{* * *} \\
(0.0190)\end{array}$ & $\begin{array}{l}-0.0593^{* * *} \\
(0.0114)\end{array}$ & $\begin{array}{l}-0.0366^{* * *} \\
(0.0178)\end{array}$ & $\begin{array}{l}-0.0586^{* * *} \\
(0.0123)\end{array}$ \\
\hline EDUCATION & $\begin{array}{l}-3.6162^{* * *} \\
(0.1610)\end{array}$ & $\begin{array}{l}0.7116^{* * *} \\
(0.0906)\end{array}$ & $\begin{array}{l}-9.7805^{* * *} \\
(0.1393)\end{array}$ & $\begin{array}{l}0.6956^{* * *} \\
(0.2057)\end{array}$ \\
\hline MINORITY & $\begin{array}{l}-0.7471^{* * *} \\
(0.1648)\end{array}$ & $\begin{array}{l}-1.5924^{* * *} \\
(0.0734)\end{array}$ & $\begin{array}{l}-1.6073^{* * *} \\
(0.1503)\end{array}$ & $\begin{array}{l}-0.5955^{* * *} \\
(0.1211)\end{array}$ \\
\hline $\begin{array}{l}\text { Product Fixed Effects } \\
\text { Premium Stores } \\
\text { Border Stores } \\
\text { Holiday Period }\end{array}$ & $\begin{array}{l}\mathrm{Y} \\
\mathrm{Y} \\
\mathrm{Y} \\
\mathrm{Y}\end{array}$ & $\begin{array}{l}\mathrm{Y} \\
\mathrm{N} \\
\mathrm{Y} \\
\mathrm{Y}\end{array}$ & $\begin{array}{l}\mathrm{Y} \\
\mathrm{Y} \\
\mathrm{N} \\
\mathrm{Y}\end{array}$ & $\begin{array}{l}\mathrm{Y} \\
\mathrm{Y} \\
\mathrm{Y} \\
\mathrm{N}\end{array}$ \\
\hline $\begin{array}{l}\text { Elasticity Statistics: } \\
\text { Average } \\
\text { Sales-weighted Avg. } \\
\text { Percentage Inelastic } \\
\text { Off-Premise Demand }\end{array}$ & $\begin{array}{r}-3.32 \\
-3.11 \\
0.02 \\
-1.86\end{array}$ & $\begin{array}{r}-3.06 \\
-2.83 \\
0.08 \\
-1.84\end{array}$ & $\begin{array}{r}-3.35 \\
-3.15 \\
0.01 \\
-1.95\end{array}$ & $\begin{array}{r}-2.93 \\
-2.75 \\
0.15 \\
-1.63\end{array}$ \\
\hline $\begin{array}{l}\chi^{2}(\mathrm{df}) \\
\text { Observations } \\
\text { Markets } \\
\text { Agents per Market }\end{array}$ & $\begin{array}{r}79.0(13) \\
1,104,204 \\
9,530 \\
100\end{array}$ & $\begin{array}{r}89.1(13) \\
895,442 \\
8,282 \\
100\end{array}$ & $\begin{array}{r}74.5(13) \\
932,541 \\
8,170 \\
100\end{array}$ & $\begin{array}{r}27.8(10) \\
923,474 \\
8,104 \\
100\end{array}$ \\
\hline
\end{tabular}

Robust standard errors reported in parentheses with p-values denoted by ${ }^{*} p<0.10,{ }^{* *} p<0.05$, and $* * *$ $p<0.01$. "Off-Premise Spirit Demand" is the price elasticity of total PLCB spirit sales (750ml bottles). 


\section{The Upstream Spirit Manufacturing Market}

C.1 Wholesale Prices in other Control States Table C.1 compares the wholesale prices of Pennsylvania to that of other control states. We find there exists large degree of variation in wholesale price across control states suggesting that it is difficult to systematically compare the PLCB's wholesale prices to those in other states - each of which uses a different regulatory regime.

\section{Table C.1: Wholesale Cost Comparison to Pennsylvania by Spirit Type and Control State}

\begin{tabular}{|c|c|c|c|c|c|c|c|c|c|c|}
\hline \multirow[b]{2}{*}{ Spirit Type } & \multicolumn{2}{|c|}{$\mathrm{NC}$} & \multicolumn{2}{|c|}{$\mathrm{NH}$} & \multicolumn{2}{|c|}{$\mathrm{OH}$} & \multicolumn{2}{|c|}{$\mathrm{VT}$} & \multicolumn{2}{|c|}{ VA } \\
\hline & $\% \Delta$ & $\overline{\% \Delta>0}$ & $\% \Delta$ & $\overline{\% \Delta>0}$ & $\% \Delta$ & $\overline{\% \Delta>0}$ & $\% \Delta$ & $\overline{\% \Delta>0}$ & $\% \Delta$ & $\% \Delta>0$ \\
\hline GIN & -23.38 & 5.56 & -8.46 & 11.11 & -13.63 & 12.50 & 7.85 & 58.33 & -12.98 & 0.00 \\
\hline RUM & -21.54 & 0.00 & -2.09 & 30.77 & -4.20 & 22.73 & 11.92 & 96.00 & -6.68 & 8.82 \\
\hline TEQUILA & -10.46 & 13.04 & -4.13 & 36.00 & 2.05 & 45.45 & 23.36 & 93.75 & -7.97 & 12.00 \\
\hline VODKA & -6.29 & 1.59 & -6.70 & 16.67 & -9.32 & 28.89 & 18.91 & 97.67 & 1.70 & 5.36 \\
\hline WHISKEY & -19.46 & 1.59 & -5.12 & 21.57 & -7.47 & 20.00 & 11.53 & 83.33 & -8.99 & 17.74 \\
\hline ALL PRODUCTS & -14.94 & 3.02 & -5.18 & 22.80 & -6.85 & 25.63 & 14.81 & 88.89 & -5.75 & 10.26 \\
\hline
\end{tabular}

Wholesale costs computed using the markup formula and data on shelf prices for each state during 2005. "\% $\Delta "$ is the average percent difference relative to the $P L C B$ 's wholesale cost while "\% $\%$ " is percent of products with greater wholesale cost than Pennsylvania.

C.2 Endogenizing Wholesale Price A concern under each policy experiment may be that the upstream manufacturers (i.e., the distillers) will negotiate different wholesale prices in response to the $P L C B$ 's change in retail price. We check the robustness of our results to a model in which we allow distillers to modify the wholesale prices $\left(c^{w}\right)$ they charge the $P L C B$ in each policy experiment.

Our approach follows Villas-Boas (2007) to recover marginal costs in the upstream market where there exists $U$ upstream manufacturers, each producing some subset $\mathcal{F}_{u}$ of the $j=1, \ldots, J$ brands. At the beginning of the year, each upstream manufacturer $u$ chooses the set of wholesale prices in its product portfolio to maximize profit:

$$
\max _{\left\{c_{j}^{w}\right\}_{j \in \mathcal{F}_{u}}} \sum_{j \in \mathcal{F}_{U}} \sum_{t=1}^{T} \sum_{l=1}^{L}\left(c_{j}^{w}-c_{j}\right) M_{l} s_{j l t}(p)
$$

where $p$ is the vector of prices chosen by the $P L C B$ under equations (11a) or (11b). Profit maximization in the upstream market implies that $c^{w}$ solves the following set of first-order conditions:

$$
c^{w}-c=-\left(T_{w} \times \Delta_{w}\right)^{-1} s(p)
$$


where we have defined $T_{w}$ as the upstream ownership matrix with element $(j, m)$ equal to one when products $j$ and $m$ are both sold by the same manufacturer and is zero otherwise. The matrix $\Delta_{w}$ contains the derivatives of all product sales with respect to changes in wholesale prices. Consequently, this matrix is complex as it not only accounts substitution patterns amongst products in response to a change in retail price, but also the interaction of cross-price elasticities from changes in wholesale costs.

We use the interaction of our data, the demand estimates, and (C.2) to recover the marginal costs $(c)$ of the distillers from the benchmark estimation. For each policy experiment, we then solve for the Bertrand-Nash equilibrium in which the wholesale prices $\left(c^{w}\right)$ chosen by the distillers under equation (C.2) and the retail markups chosen by the $P L C B$ under equations $11 \mathrm{a}$ ) or $11 \mathrm{~b}$ ) are consistent.

Table C.2 presents a summary of the results across policy experiments and Table C.3 presents the change in wholesale price $\left(c^{w}\right)$ from the benchmark to the product-specific pricing experiment. Both tables show that endogenizing the wholesale prices has little quantitative or qualitative impact.

Table C.2: Counterfactuals Summary Statistics (Flexible Wholesale Prices)

\begin{tabular}{lrrrrr}
\hline \hline Scenario & Profits & CS & Welfare & Quantity & Price \\
\hline 30\% UNIFORM MARKUP & 53.79 & 57.89 & 111.68 & 8.56 & 15.39 \\
UNIFORM П-MAXIMIZING MARKUP (32.4\%) & 54.49 & 56.01 & 110.50 & 8.39 & 15.54 \\
PRODUCT-SPECIFIC & 60.49 & 50.51 & 111.00 & 7.82 & 18.87 \\
3RD DEGREE PRICE DISCRIMINATION & 63.05 & 49.74 & 112.79 & 8.17 & 18.91 \\
\hline
\end{tabular}

Profits, consumer surplus (CS), and welfare are denominated in millions of dollars. Profits include liquor taxes. Quantity is millions of $750 \mathrm{ml}$ bottles. "Price" is average sales-weighted price.

Table C.3: Changes in Wholesale Price by Spirit Type

\begin{tabular}{lcccccc}
\hline \hline \multirow{2}{*}{ Spirit Type } & \multicolumn{2}{c}{ Weighted Average Price $\left(c^{w}\right)$} & & \multicolumn{3}{c}{ Distribution of Price Changes (\%) } \\
\cline { 2 - 3 } \cline { 5 - 6 } \cline { 5 - 6 } GIN & Current & Product & & Avg & SD & $\% \Delta>0$ \\
RUM & 8.57 & 8.54 & & -0.20 & 0.46 & 43.01 \\
TEQUILA & 7.22 & 7.22 & & -0.07 & 0.25 & 44.59 \\
VODKA & 12.80 & 12.70 & & -0.65 & 0.35 & 5.28 \\
WHISKEY & 9.56 & 9.52 & & -0.46 & 0.38 & 9.91 \\
\hline CHEAP & 9.47 & 9.43 & & -0.34 & 0.40 & 21.90 \\
EXPENSIVE & 6.53 & 6.51 & & -0.28 & 0.47 & 42.74 \\
ALL PRODUCTS & 12.42 & 12.37 & & -0.39 & 0.28 & 3.62 \\
\hline
\end{tabular}




\section{Computing Retail Prices}

In this Appendix, we provide computational details for the procedures we employ to find the profit-maximizing prices under alternative $P L C B$ pricing mechanisms. We first consider a multi-product monopolist's pricing problem in a given market $l$ and time period $t$ only. The monopolist solves this same problem for each local market $l$ and time period $t$. The firm chooses a vector $p_{\cdot l}$ to solve

$$
\max _{p \cdot l} \sum_{j \in J_{l}}\left(p_{j l}-c_{j}^{w}\right) M_{l} s_{j l}\left(p_{\cdot l}\right)
$$

where we suppress the time period index $t$ for ease of exposition.

The firm's first-order condition associated with profit maximization in market $l$ is given by

$$
s_{j l}\left(p_{\cdot l}\right)+\sum_{r \in J_{l}}\left(p_{r l}-c_{r}^{w}\right) \frac{\partial s_{r l}\left(p_{\cdot l}\right)}{\partial p_{j l}}=0 .
$$

Optimality requires that Equation (D.2) hold for all products sold in market $l$. We express the set of $J_{l}$ first-order conditions in matrix notation as

$$
s\left(p_{\cdot l}\right)+\Omega\left(p_{\cdot l}-c^{w}\right)=0,
$$

where an element of the matrix $\Omega$ is defined as

$$
\Omega_{j r}=\left\{\begin{array}{cc}
\frac{\partial s_{j l}\left(p_{\cdot l}\right)}{\partial p_{r l}}, & \text { if }\{j, r\} \subset J_{l}, \\
0 & \text { otherwise } .
\end{array}\right.
$$

For a given vector of marginal $\operatorname{costs} c^{w}$, we find the fixed point to the system of equations defined in Equation (D.3) numerically. To this end, define the following operator

$$
T\left(p_{. l}^{o}\right)=c^{w}-\Omega^{-1}\left(p_{. l}^{o}\right) \times s\left(p_{. l}^{o}\right)
$$

where the equilibrium prices are such that $p^{n}=T\left(p^{o}\right)$. When $\left\|p^{n}-p^{o}\right\|_{\infty}$ is sufficiently small, then the first-order condition defined in Equation (D.3) necessarily holds and $p^{n}$ contains the set of optimal prices in each market. 
In the "Product-Specific" counterfactual we constrain the monopolist to set prices for product $j$ that are constant across all markets $l$. The monopolist then chooses a vector of prices $p$ to solve

$$
\max _{p} \sum_{j \in J} \sum_{l \in L}\left(p_{j}-c_{j}^{w}\right) M_{l} s_{j l}(p) \equiv \max _{p} \sum_{j \in J}\left(p_{j}-c_{j}^{w}\right) \sum_{l \in L} M_{l} s_{j l}(p)
$$

which yields the following first-order condition for product $j$ in market $l$

$$
\sum_{l \in L} M_{l} s_{j l}(p)+\left[\sum_{r \in J}\left(p_{r}-c_{r}^{w}\right) \sum_{l \in L} M_{l} \times \frac{\partial s_{r l}(p)}{\partial p_{j}}\right]=0
$$

Alternatively, in matrix notation

$$
\tilde{s}(p)+\tilde{\Omega}\left(p-c^{w}\right)=0
$$

where

$$
\begin{aligned}
& \tilde{s}_{j}(p)=\sum_{l \in L} M_{l} s_{j l}, \\
& \tilde{\Omega}_{j}(p)=\left\{\begin{array}{cc}
\sum_{l \in L} M_{l} \times \frac{\partial s_{j l}(p)}{\partial p_{r}}, & \text { if }\{j, r\} \subset J_{l}, \\
0 & \text { otherwise }
\end{array}\right.
\end{aligned}
$$

We again solve for the optimal prices using the operator defined in (D.5).

In the "Uniform П-max" counterfactual, we employ a grid search to find the value of $\lambda$ that maximizes

$$
\max _{\lambda \in[0,1]} \sum_{j \in J_{l}} \sum_{l \in L}\left(\hat{p}_{j}(\lambda)-c_{j}^{w}\right) M_{l} s_{j l}(\hat{p})
$$

where

$$
\hat{p}_{j}(\lambda)=\left[(1+\lambda) c_{j}^{w}+\$ 1.20\right] \times 1.18
$$

holding the $P L C B$ 's handling charges and liquor tax rate fixed at the current levels. 


\section{Web Appendix - Not for Publication}

\section{Table W.1: Correlation Amongst Demographics}

\begin{tabular}{lccccc}
\hline \hline Statistic & POPULATION & MINORITY & AGE $\geq 45$ YRS & HIGH INCOME & EDUC $\geq$ COLLEGE \\
\hline POPUlATION & 1.00 & - & - & - & - \\
MINORITY & 0.32 & 1.00 & - & - & - \\
AGE $\geq 45$ YRS & 0.19 & 0.34 & 1.00 & - & - \\
HIGH INCOME & 0.06 & -0.24 & -0.32 & 1.00 & - \\
EDUC $\geq$ COLLEGE & 0.05 & -0.01 & 0.08 & 0.70 & 1.00 \\
\hline
\end{tabular}

Table W.2: Income Distribution Estimates

\begin{tabular}{lrrrr}
\hline \hline & \multicolumn{4}{c}{ Generalized Beta } \\
\cline { 2 - 5 } Statistics & $a$ & $p$ & $q$ & $b$ \\
\hline MEAN & 2.1 & 3.0 & 6346.4 & 59410.6 \\
SD & 5.6 & 42.1 & 14022.6 & 305136.9 \\
MiN & 0.1 & 0.0 & 0.7 & 34.9 \\
MAX & 123.9 & 929.2 & 228663.0 & 5997629.5 \\
\hline
\end{tabular}

Summary statistics for a set of 484 maximum-likelihood estimates of income distributions. We assume that each empirical income distribution follows a generalized beta distribution with probability density function:

$$
f(x)=\frac{a x^{a-p-1}}{b^{a p} B(p, q)\left[1+\left(\frac{x}{b}\right)^{a}\right]^{p+q}}, \quad x>0,
$$

where $B(p, q)=\Gamma(p) \Gamma(q) / \Gamma(p+q)$, and $\Gamma(\cdot)$ is the gamma function, while $a, p$, and $q$ are shape parameters and $b$ is a scale parameter. 


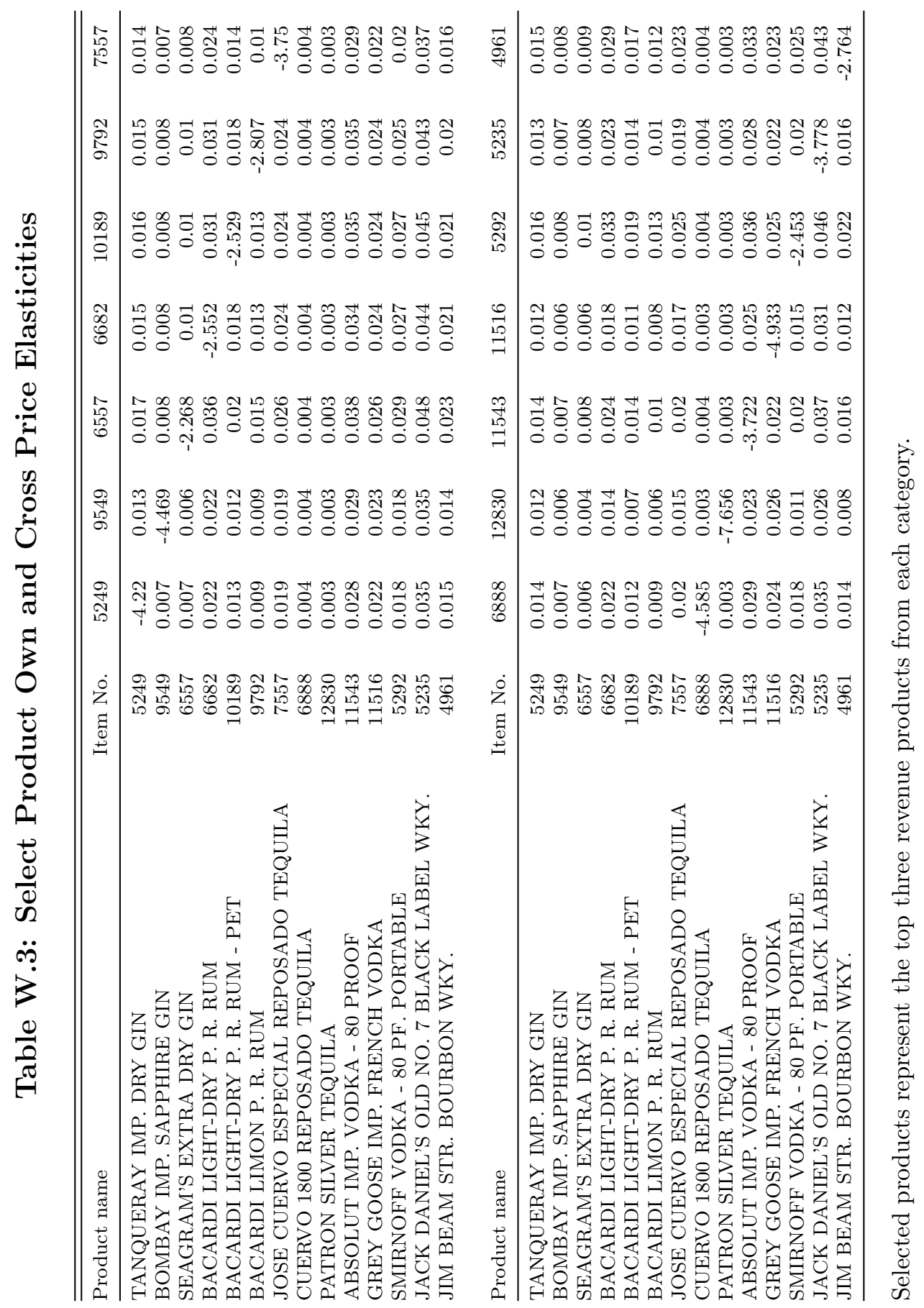


Table W.4: Most Popular Products by Income Decile

\begin{tabular}{lrr}
\hline \hline Spirit Product & Price & Share \\
\cline { 1 - 2 } Bottom Income Decile $\mathbf{( \$ 3 1 , 0 2 0 ) :}$ & & \\
\cline { 1 - 2 } 1. BACARDI LIGHT-DRY P. R. RUM & & \\
2. JACK DANIEL'S OLD NO. 7 BLACK LABEL & 12.32 & 1.77 \\
3. ABSOLUT IMP. VODKA - 80 PROOF & 19.32 & 1.18 \\
4. SEAGRAM'S EXTRA DRY GIN & 18.97 & 1.16 \\
5. FIVE O'CLOCK EXTRA DRY GIN & 10.78 & 1.15 \\
6. NIKOLAI VODKA - 90 PROOF & 6.07 & 1.12 \\
7. BACARDI LIMON P. R. RUM & 6.85 & 1.09 \\
8. SMIRNOFF VODKA - 80 PROOF & 13.67 & 1.02 \\
9. JACQUIN'S WHITE RUM & 11.79 & 0.82 \\
10. GREY GOOSE IMP. FRENCH VODKA & 7.99 & 0.79 \\
\hline Average Number of Products: 117.9 & 26.64 & 0.77 \\
\hline
\end{tabular}

Top Income Decile $(\$ 74,440)$ :

$\begin{array}{lll}\text { 1. ABSOLUT IMP. VODKA - 80 PROOF } & 18.97 & 1.76\end{array}$

2. SMIRNOFF VODKA - 80 PF. PORTABLE $\quad 11.84 \quad 1.64$

3. JACK DANIEL'S OLD NO. 7 BLACK LABEL $19.32 \quad 1.54$

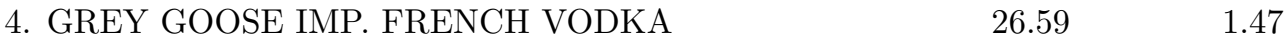

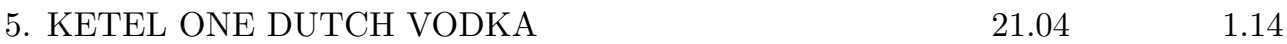

6. SMIRNOFF VODKA - 80 PROOF $\quad 11.79 \quad 1.08$

7. BACARDI LIGHT-DRY P. R. RUM $12.32 \quad 1.01$

8. JOSE CUERVO ESPECIAL REPOSADO TEQUILA $19.11 \quad 0.99$

$\begin{array}{lll}\text { 9. SKYY VODKA } & 15.39 & 0.92\end{array}$

10. TANQUERAY IMP. DRY GIN $\quad 21.99 \quad 0.73$

Avg. Number of Products: 148.8

Liquor products sorted by share of sales of $750 \mathrm{ml}$ bottles of spirits. 
Figure W.1: Retail Price Across Time, Selected Products

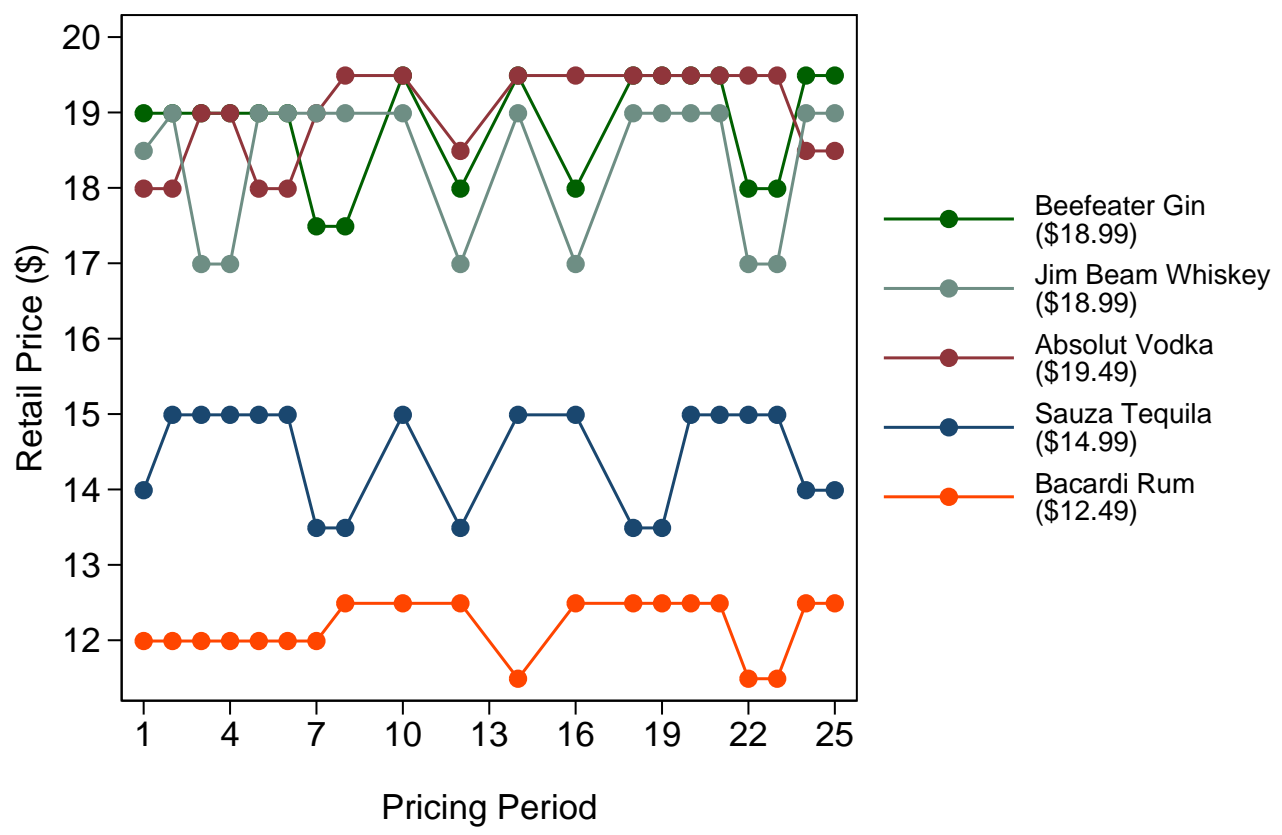

Figure W.2: Distribution of the Price Coefficient

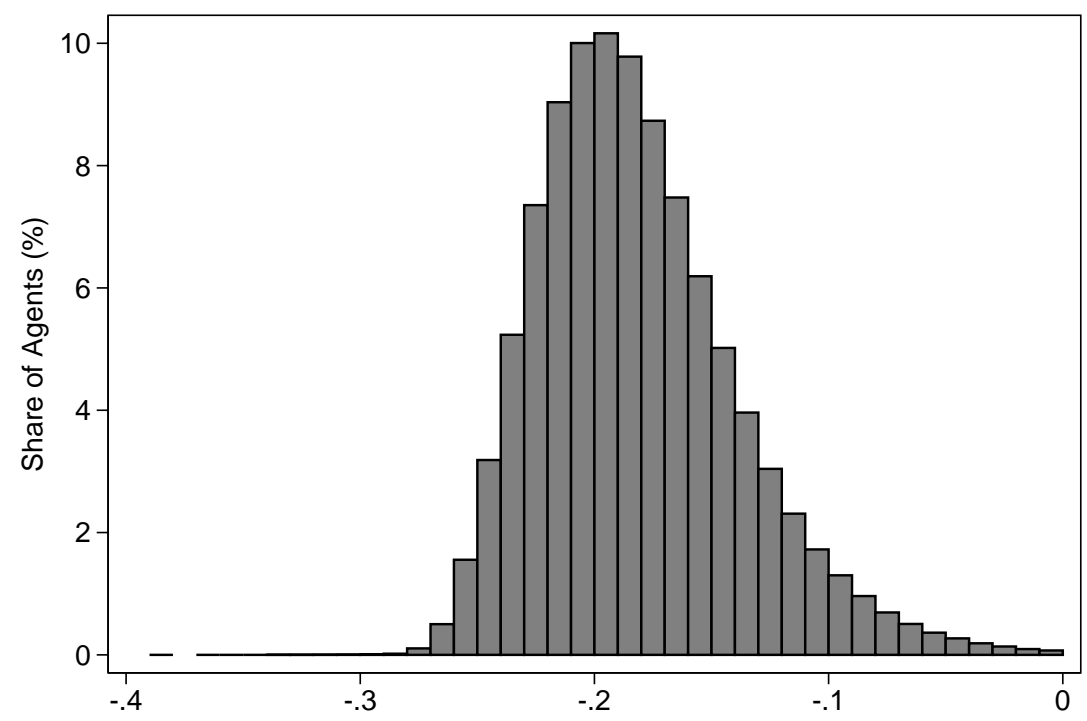


Figure W.3: Distribution of Compensating Variation by Market Demographics
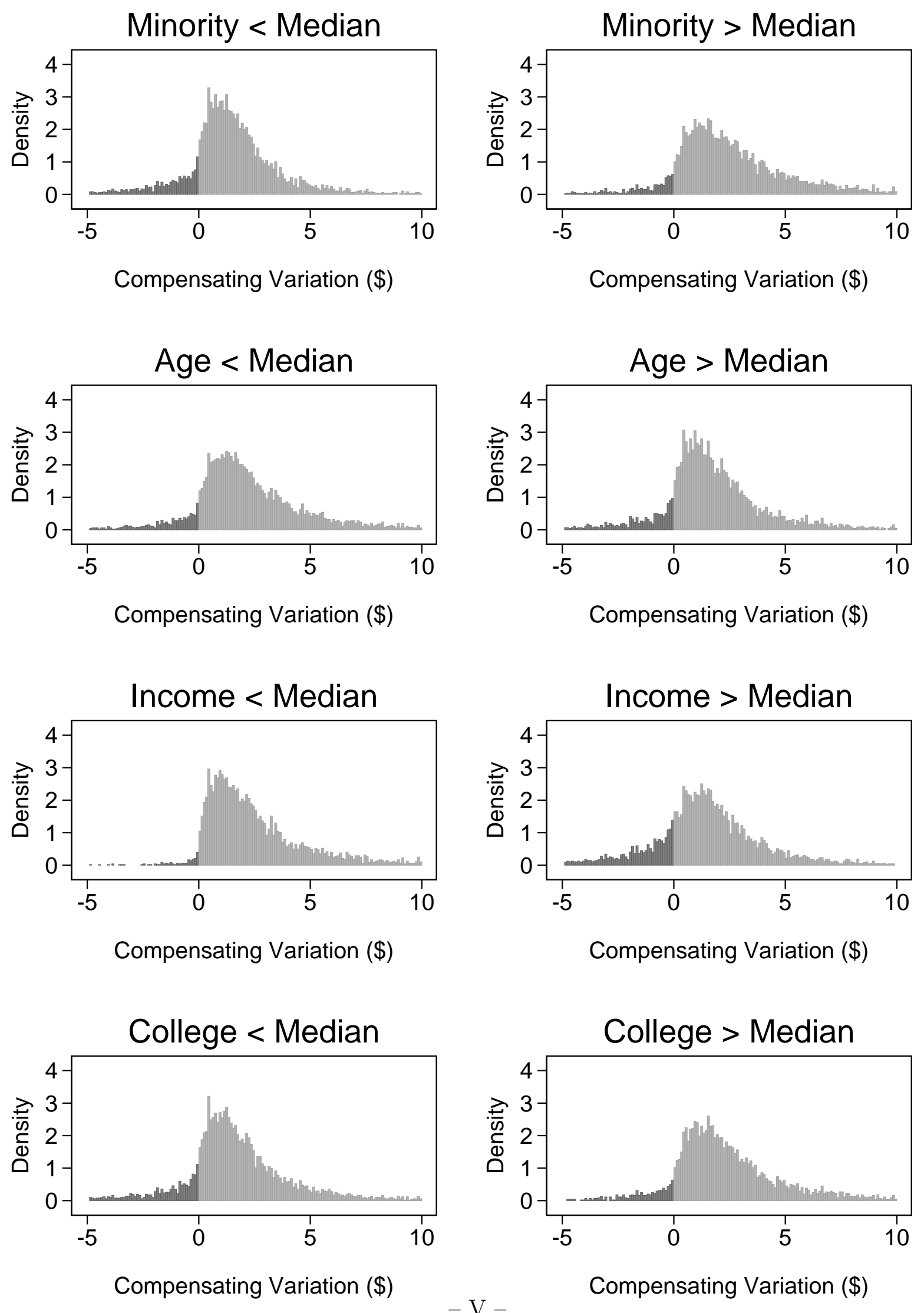
Figure W.4: Distribution of Price and Market Share: Product-Specific vs Benchmark Uniform Pricing

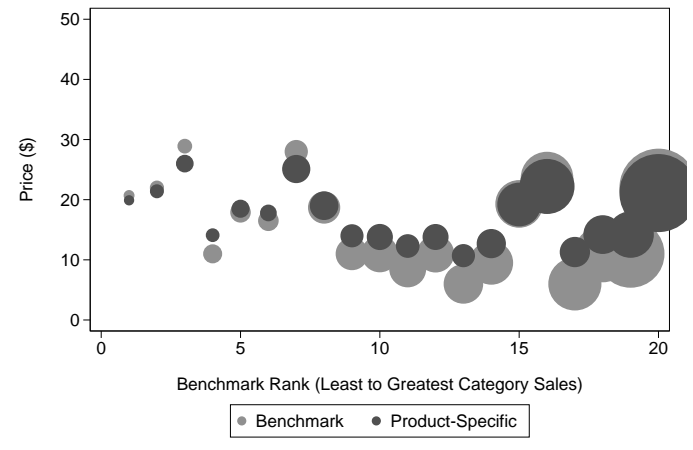

(a) Gin

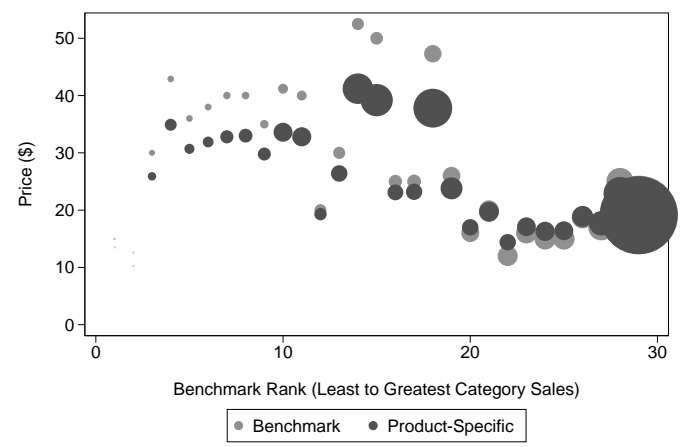

(c) Tequila

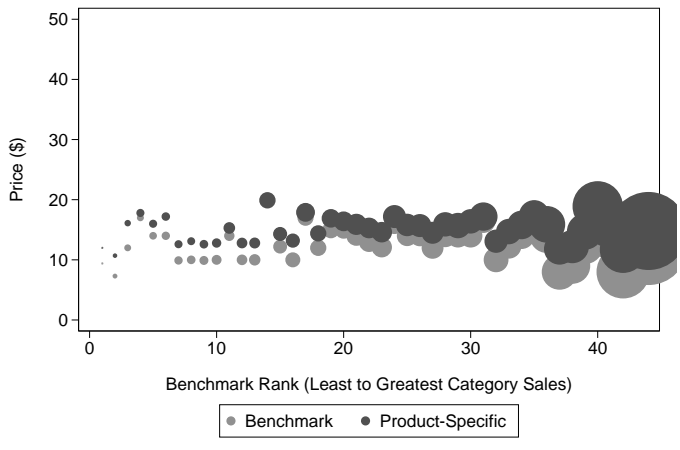

(b) Rum

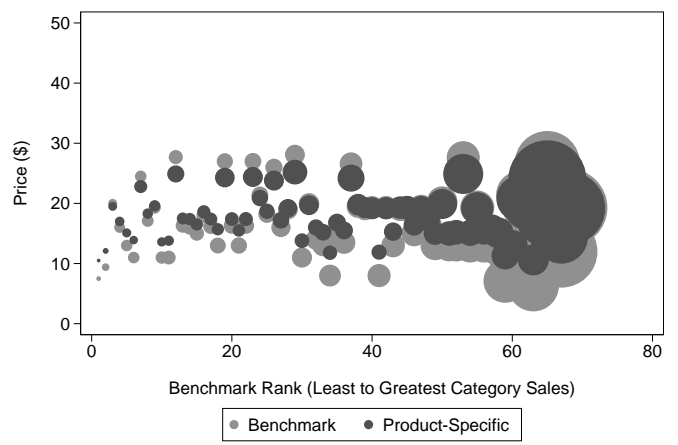

(d) Vodka

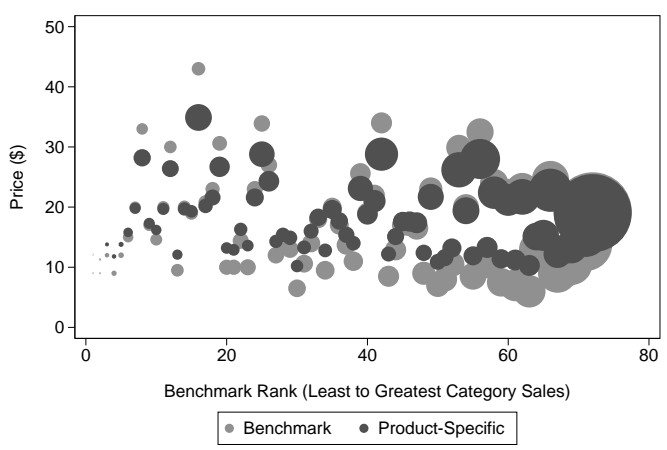

(e) Whiskey 